\title{
6 Zum Zusammenspiel von Kommunikation in der und durch die Ausstellung
}

\subsection{Ausgangspunkt: Das Hinweis-Konzept}

Die Kommunikation in der Ausstellung setzt die Kommunikation durch die Ausstellung voraus: Ohne das multimodale Kommunikationsangebot im Ausstellungsraum kann es die Kommunikation in der Ausstellung, wie sie uns in Kapitel 5 begegnet ist, nicht geben.

Tatsächlich haben wir im letzten Kapitel gesehen, dass die Situierung der Interaktion im Museum immer wieder an dem ansetzt, was die Besucher im Ausstellungsraum vorfinden: die interaktive Herstellung des museumsspezifischen Bewegungsraums mit seiner charakteristischen Organisation in Geh- und Verweilzonen, die Herstellung des musealen Betrachtungsraums mit den Exponaten im Zentrum sowie die Herstellung des musealen Handlungsraums und seine Nutzung für eine spezifische anschauungsbasierte Wissenskonstruktion. Diese Nutzung der raumgebundenen Erscheinungsformen der Kommunikation durch die Ausstellung im Rahmen der Kommunikation in der Ausstellung soll nun systematisch untersucht werden.

Um die Verbindung zwischen dem semiotisch reichen Ausstellungsraum und der Interaktion der Besucher in diesem Raum untersuchen zu können, greife ich auf das Konzept der „Lesbarkeitshinweise“ (anfangs: „Textualitätshinweise“) zurück, das zunächst für die Analyse von Textkommunikation entwickelt worden ist (Hausendorf/Kesselheim 2008, Hausendorf et al. 2017). In jüngerer Zeit wurde verschiedentlich die Übertragbarkeit dieses Konzepts auf andere Formen von Dauerkommunikation erprobt, etwa unter dem Label „Benutzbarkeitshinweise“ (Hausendorf/Kesselheim 2016) oder - mit Bezug auf Räume in Videospielen als „orientation cues“ (Kato/Bauer 2019). Das Hinweis-Konzept erlaubt eine Refokussierung und Fortführung der Analysen der Kommunikation durch die Ausstellung in Kapitel 3. Ausgangspunkt der Analysen in Kapitel 3 war die Überlegung, dass sich der Ausstellungsraum als Material gewordene Lösung eines kommunikativen Problems auffassen lässt. Daraufhin wurde im Ausstellungsraum eine große Fülle multimodaler Formen identifiziert, die sich als Lösung dieses Problems bzw. genauer: als Bearbeitung der sich aus jenem ergebenden (Teil-)Aufgaben verstehen ließen.

Genau diese als Problemlösung entstandenen Erscheinungsformen im Ausstellungsraum können nun - das ist die Idee, die den folgenden Analysen zugrunde liegt - von den Besuchern als Hinweise für ihre eigene Nutzung dieses Raums aufgefasst werden. Anders gesagt: In dem Maß, wie die Lösung für ein wiederkehrendes kommunikatives Problem und seine Aufgaben sich gleichsam 
zu materiellen Formen im Raum verdichtet hat, haben diese Formen Appelloder eben: Hinweis-Charakter für zukünftige Problemlösungen. Sie werden von Raumnutzern auf die Frage hin ausgewertet, wie sie den Raum aktuell nutzen sollen. So können beispielsweise genau die Formen, die als Lösung für das Problem entstanden sind, wie man Besuchern signalisieren kann, dass sie in einem bestimmten Raumbereich stehen bleiben sollen, von Raumnutzern als Hinweis ausgewertet werden, der ihnen signalisiert, dass ein Stehenbleiben an dieser Stelle ,vorgesehen ist', dass es sich um einen Bereich handelt, der dem Verweilen ,dient".

Die Re-Perspektivierung der Befunde aus Kapitel 3 mit Hilfe des HinweisKonzepts ermöglicht es, zu untersuchen, wie die kommunikativen Erscheinungsformen im Ausstellungsraum, die in Kapitel 3 beschrieben worden sind, in der Kommunikation in der Ausstellung wirksam werden. Aus der Sicht des HinweisAnsatzes nämlich gewinnen die Besucher aus solchen sinnlich wahrnehmbaren Formen Hinweise, die sie als Antwort auf Fragen verstehen wie Wo soll ich langgehen? Wo soll ich stehen bleiben? Wohin soll ich schauen?, aber auch auf Fragen wie Wovon ist hier im Raum die Rede? Welche kommunikative Funktion kommt dem im Raum Vorgefundenen zu? Geht es hier um Genuss oder um die Beschäftigung mit Wissenschaft? usw. Die Besucher können diese Hinweise aus unterschiedlichen ,Quellen' gewinnen (s. analog Hausendorf et al. 2017: 69-105):

- aus der Wahrnehmung (man denke etwa an die Nähe zwischen zwei Exponaten, die als Hinweis darauf verstanden werden kann, dass sie als zusammengehörig betrachtet werden sollen),

- aus der Sprache (s. etwa ein anaphorisches Pronomen, das als Hinweis verstanden werden kann, dass der gerade gelesene Satz mit einem vorausgegangenen zu verknüpfen ist) sowie

- aus einer zuvor erworbenen Vertrautheit mit relevanten Kontexten, in denen die betreffenden Hinweise vorkommen (wer aus seiner Vorerfahrung mit Museen weiß, dass immer eine Objektkennung und ein Exponat zusammengehören, der kann dies als Hinweis auf eine Verbindung nutzen, selbst, wenn einmal die Objektkennung zu weit von ,ihrem Exponat entfernt ist). ${ }^{1}$

Diese Quellen schließen einander nicht aus. So hat Sprache immer auch ein wahrnehmbares „Gewand“ (Stöckl 2004), eine wahrnehmbare Laut- oder Schriftform, aus der Hinweise gewonnen werden können, selbst wenn man die betref-

1 Die unterschiedlich ausgeprägte Vertrautheit mit den relevanten Rezeptions- und Lektürekontexten ist oft dafür verantwortlich, dass unterschiedliche Personen Unterschiedliches als Hinweis interpretieren oder Hinweise auf unterschiedliche Weise interpretieren können. 
fende Sprache nicht versteht (s. Hausendorf et al. $2017 \mathrm{zu}$ „Materialität“ und „Skripturalität“). Umgekehrt gibt es wohl kaum Hinweise, die ausschließlich auf Perzeption beruhten, ohne dass ein kulturelles oder sprachliches Vorwissen zu ihrem vollständigen Verständnis notwendig wäre. So mag der schmale Zugang zum Kassenbereich wahrnehmungsbasiert als Hinweis verstanden werden, dass hier keine großen Menschenmengen erwartet werden. Dass es sich aber um einen exklusiven Bereich für das Museumspersonal handelt, lässt sich wohl nur vertrautheitsbasiert erschließen. Weiterhin gilt es $\mathrm{zu}$ beachten, dass Hinweise aus den unterschiedlichsten Materialien bestehen und über die alle Sinne wahrgenommen werden können. Als Hinweis kommt grundsätzlich alles infrage, was im Ausstellungsraum auf irgendeine Art und Weise wahrgenommen werden kann: Exponate und alle ihre mit den Sinnen erfassbaren Eigenschaften, Bilder, Schrift, Türen, Treppen, Vitrinen, Formen, Materialien, Farben usw. Entscheidend ist nur: Ein Hinweis muss, um in der Situation der Rezeption der Ausstellung wirksam werden zu können, auf irgendeine Weise wahrnehmbar sein. Das gilt selbst für die vertrautheitsbasierten Hinweise. Irgendetwas muss im Raum wahrnehmbar sein, das als Signal verstanden werden kann, dass ein bestimmtes Vorwissen zu aktivieren ist.

Hinweise können auf eine bestimmte körperliche Nutzung des Raums gerichtet sein und beispielsweise bestimmte Bewegungen, bestimmte Blickrichtungen usw. erwartbar machen. Diese „Benutzbarkeitshinweise“ (Hausendorf 2012, Hausendorf/Kesselheim 2016) spielen in der Kommunikation in der Ausstellung speziell dort eine Rolle, wo es um die Herstellung des Interaktionsraums geht, nämlich indem sie Möglichkeiten und Beschränkungen dafür erkennbar machen, wie der gemeinsame Bewegungs-, Wahrnehmungs- und Handlungsraum für die soziale Praxis des gemeinsamen Museumsbesuchs gestaltet und genutzt werden kann. Darüber hinaus sind für die Ausstellungskommunikation aber auch die „Lesbarkeitshinweise" relevant, die von der Textlinguistik bisher im Zusammenhang mit der Analyse v.a. schriftbasierter Kommunikation untersucht worden sind. ${ }^{2}$ Diese

geben typischerweise eine Antwort auf Fragen kognitiver Natur (wie: worum geht es? was ist der Zweck, den der Text verfolgt?), jedenfalls sehr viel seltener eine Antwort auf Probleme der Sensorik und der Motorik (wie: wohin muss ich jetzt gehen?) [...] und fast nie eine Antwort auf Probleme der Ko-Orientierung von Wahrnehmungen, der Ko-Ordinierung von Bewegungen und der Ko-Operation unter Anwesenden. (Hausendorf/Kesselheim 2016: 19)

2 Tatsächlich ist die Grenze zwischen diesen beiden Arten von Hinweisen fließend, wie die Analysen in 3.3 belegen, die die Bedeutung von Wahrnehmung und Bewegung beispielsweise für die Gliederung des kommunikativen Angebots oder die Konstruktion eines thematischen Zusammenhangs nachweisen. 
Dass Lesbarkeitshinweise im Rahmen der Kommunikation in der Ausstellung eine Rolle spielen, ist nicht überraschend, wenn man sich vor Augen hält, dass eine Besonderheit des Ausstellungsraums ja gerade darin besteht, dass er eine Nutzung zu kommunikativen Zwecken hochgradig erwartbar macht - und das nicht nur in dem Sinn, dass Exponate, wie wir in 3.6 gesehen haben, als Zeichen verstanden werden: im Ausstellungsraum wird tatsächlich auch gelesen.

Benutzbarkeitshinweise darf man sich nun nicht als Schilder vorstellen, die eine bestimmte Nutzung des Raums verlangen oder verbieten („Kein Durchgang“). Auch schon die physische Möglichkeit oder Unmöglichkeit, einen Raum auf eine bestimmte Art und Weise zu nutzen, kann von den Besuchern als Hinweis verstanden werden: Das Absperrseil verhindert nicht nur ein Weitergehen, es kann schon von Ferne als Signal ausgewertet werden, dass es an dieser Stelle im Raum nicht weitergeht (und folglich: dass man dort nicht weitergehen soll); und eine breite Lücke in einem ansonsten durchgehenden Geländer ermöglicht nicht nur rein physisch ein Durchgehen, sie kann als Hinweis darauf verstanden werden, dass hier ein Durchgehen möglich (und folglich: erwartbar) ist. ${ }^{3}$

Die Analyse von Benutzbarkeitshinweisen ist, wie diese Beispiele schon erkennen lassen, unmittelbar anschlussfähig zu Arbeiten, die auf den Konzepten „Interaktionsarchitektur“ und „Sozialtopographie“ beruhen (s. die Arbeiten in Hausendorf/Schmitt/Kesselheim 2016, insbesondere Hausendorf/Schmitt 2016). Während die Analyse der „Interaktionsarchitektur“ Benutzbarkeitshinweise rekonstruiert, die auf eine spezifische Nutzung des Raum, nämlich für Formen der sozialen Interaktion hinweisen, lassen sich sozialtopographische Rekonstruktionen gut als Analysen von Benutzbarkeitshinweisen auffassen, für deren Ausschöpfung ganz spezifisch der Rückgriff auf die Quelle der Vertrautheit notwendig ist.

Wie aber lässt sich die Auswertung der Hinweise durch die Besucher in meinen Videodaten beobachten? Hierfür lässt sich das in Kapitel 4 bereits beschriebene konversationsanalytische Prinzip des display ausnutzen: Die Interaktionsbeteiligten zeigen sich gegenseitig den Sinn ihrer Handlungen auf, und diese Aufzei-

3 Die Auswertung solch basaler Benutzbarkeitshinweise wird allerdings nur unter dem methodischen Druck der Verfremdung als interaktive Realisierung eines Hinweises sichtbar. Empirisch ergiebiger wird die Hinweis-Analyse, wenn es sich um spezifischere Benutzbarkeitshinweise handelt (z.B. die Nutzung eines Exponats für das anschauungsbasierte Erkennen zoologischer Sachverhalte) oder wenn der Aufwand, mit dem sich die Besucher gegenseitig ihre Nutzung eines Hinweises aufzeigen, besonders auffällig wird: etwa im gegenseitigen Sich-etwas-Vorlesen oder in der aufwändigen, multimodalen Inszenierung der stillen Betrachtung eines Exponats. Hier erlaubt die Hinweis-Analyse einen neuen Blick auf einige grundlegende Besonderheiten der Kommunikation in der Ausstellung, die in Kapitel 5 rekonstruiert worden sind. 
geaktivitäten hinterlassen in den Videodaten sicht- und hörbare Spuren, die für die Analyse genutzt werden können (s. wieder Deppermann 1999: 50). Für die Kommunikation in der Ausstellung heißt das: Wenn die Benutzbarkeits- und Lesbarkeitshinweise im Ausstellungsraum für die Interaktion der Besucher relevant werden sollen, müssen sich die Besucher gegenseitig anzeigen, was sie im Ausstellungsraum als Benutzbarkeits- oder Lesbarkeitshinweis auswerten. Damit ist nun nicht gemeint, dass die Besucher jede Auswertung eines Hinweises in einem eigenen Gesprächsbeitrag thematisieren oder kommentieren müssten. Vielmehr führen sie die Bezugnahme auf die Hinweise so aus, dass sie für ihre Interaktionspartner als eine solche Bezugnahme zu erkennen sind - in den Analysen dieses Kapitels werden wir zahlreiche Beispiele hierfür beobachten können. Mit anderen Worten: Indem sie den Raum im Zuge ihrer Praxis des gemeinsamen Museumsbesuchs nutzen, zeigen sich die Besucher an, was im Raum sie gerade mit welcher Bedeutung als Hinweis verstehen. Die Anwendbarkeit des Hinweis-Konzepts ist nicht auf die interaktive Nutzung der Ausstellung im Rahmen gemeinsamer Museumsbesuche beschränkt. Sie eignet sich auch dazu, die Bedeutungspotenziale $\mathrm{zu}$ rekonstruieren, die die Ausstellung einem einzelnen Besucher bereitstellt (s. dazu etwa Kesselheim 2011). Aber im gemeinsamen Museumsbesuch hinterlässt die Auswertung der Hinweise aufgrund des displays der Interaktionsbeteiligten sicht- und hörbare Spuren, die es erlauben, in einem konkreten Einzelfall empirisch zu rekonstruieren, welche Hinweise im Raum durch die Besucher aktiviert und wie sie verstanden wurden.

Bisher sind vor allem zwei Versuche unternommen worden, die statischen Strukturen, die die Interaktionsbeteiligten in ihrer räumlichen Umwelt vorfinden, in die Analyse ihrer dynamischen Interaktion einzubeziehen: Charles Goodwins Ansatz der „contextual configuration“ (s.o. 4.2.4) und das wahrnehmungspsychologische Modell der „affordances“( (s.u.).

Goodwins Konzept der „contextual configuration“ (Goodwin 2000) erlaubt es, den Rückgriff der Interaktionsteilnehmer auf körpergebundene Ressourcen (wie gesprochene Sprache, Körperposition und -haltung, Blicke usw.) und auf die räumliche Umwelt (und ihre semiotischen Strukturen: Spielfelder, Schrift usw.) in einem gemeinsamen Analysegang zu berücksichtigen:

When action is investigated in terms of contextual configurations, domains of phenomena that are usually treated as so distinct that they are the subject matter of entirely separate academic disciplines, e.g., language and material structure in the environment, can be analyzed as integrated components of a common process for the social production of meaning and action. (2000: 1490) 
So gestattet Goodwins Ansatz den Einbezug dauerkommunikativer Erscheinungsformen in die Analyse der Angesichtskommunikation. ${ }^{4}$ Allerdings entwickelt der Autor keinen speziellen methodischen Zugang, um die nicht an die Körper der Interagierenden gebundenen semiotischen Ressourcen dieser „material structure in the environment“ zu untersuchen. Diesen Zugang kann, wie die Analysen dieses Kapitels im Folgenden zeigen werden, das HinweisKonzept eröffnen.

Der zweite Ansatz, der gegenwärtig häufig angeführt wird, wenn es um die Frage geht, wie die räumliche Umwelt oder Objekte in dieser Umwelt in die Analyse von Interaktion einbezogen werden soll, ist die Theorie der affordances des Wahrnehmungspsychologen James J. Gibson (s. Gibson 1979). Nach Gibson wird unsere Wahrnehmung der Umwelt durch die ,Angebote“ (so die deutsche Übersetzung seines Begriffs affordance in Gibson 1982) bestimmt, die die Umwelt für unser Verhalten oder Handeln unterbreitet. Gibson definiert den Begriff wie folgt:

Unter den Angeboten (affordances) der Umwelt soll das verstanden werden, was sie dem Lebewesen anbietet (offers), was sie zur Verfügung stellt (provides) oder gewährt (furnishes), sei es zum Guten oder zum Bösen. (Gibson 1982: 137)

Nach Gibson durchforsten wir unsere Umgebung mit ihren Objekten gezielt nach diesen affordances oder ,Angeboten': Wo können wir Schutz suchen, was kann überklettert, was kann als Sitzgelegenheit benutzt, gegessen werden, wovon geht eine Gefahr aus usw.

Die Substanzen haben biochemische Angebote und solche der Verarbeitung und Herstellung. Die Oberflächen bieten Stand, Fortbewegung, Zusammenstoß, Handhabung, allgemein gesprochen: Verhalten an. Spezielle Formen der Fläche[n]anordnung bieten sich als Unterkunft oder Versteck an. Feuer bieten Wärmen und Brennen an. Abgesonderte Objekte - Werkzeuge, Geräte, Waffen - machen Primaten und Menschen ganz spezielle Verhaltensangebote. (1982: 148)

\footnotetext{
4 Goodwins Begriff der „contextual configuration“ hat zahlreiche Untersuchungen zum Zusammenspiel von körpergebundener Modi und Strukturen in der räumlichen Umwelt inspiriert (Smith 2018), deutlich erkennbar etwa in den konversationsanalytischen Forschungssträngen zu Objekten in Interaktion (z.B. Nevile et al. 2014), zu Lerninteraktionen (etwa Zemel/Koschmann 2016), oder zu Mobilität (einführend Stefani/Broth/Deppermann 2019). Dagegen ist der Einbezug dauerkommunikativer Zeichenangebote in die Angesichtskommunikation nur selten thematisiert worden.
} 
Die Bedeutung des Raums und seiner Objekte sowie die Art und Weise, wie die Menschen den Raum und seine Objekte nutzen, ergibt sich aus diesen affordances, allerdings nicht im Sinn einer Determination, sondern im Sinn eines Aufforderns, ,Rahmens‘ (Hutchby 2001: 444) oder Erwartbar-Machens. ${ }^{5}$

Möchte man nun mit dem Begriff der affordances die Frage beantworten, wie die Besucher bei ihrem gemeinsamen Gang durch die Ausstellung die Bedeutung des Ausstellungsraums und seiner Objekte konstruieren, lautet die Antwort: Die wahrgenommenen affordances legen es den Besuchern nahe, den Ausstellungsraum und die dort arrangierten Objekte auf eine bestimmte Art und Weise zu verstehen und zu nutzen. Allerdings bietet der affordance-Ansatz zunächst keine Antwort darauf, von welchen Merkmalen des Raums oder der Objekte aus die affordances erschlossen werden können. ${ }^{6}$ Diese Antwort lässt sich aus dem Hinweis-Konzept gewinnen, wie die Analysen dieses Kapitels zeigen werden. Auch lässt sich über das Hinweis-Konzept genauer bestimmen, worin die affordance eines bestimmten Merkmals liegt, nämlich dann, wenn man die Hinweise auf die kommunikativen Teilaufgaben bezieht, die durch eine Form bearbeitet werden: etwa die Abgrenzung eines Objekts von seiner räumlichen Umwelt, die Herstellung von Bezügen $\mathrm{zu}$ anderen Objekten, die Herstellung eines thematischen Zusammenhangs, das Signalisieren einer kommunikativen Funktion usw. Die Hinweis-Analyse ermöglicht es so, detaillierter zu beschreiben, welche Elemente

\footnotetext{
5 Interessant scheint mir, dass das Auswerten der ,Angebote، durch Raumnutzer häufig mit dem Interpretieren von Zeichen in einem Kommunikationsprozess vergleichen wird. So etwa in Kruse/Graumann (1978: 190), die auch davon sprechen, dass Zeichen (gemeint sind wohl primär Schilder oder Aufschriften in der räumlichen Umwelt) eigene affordances für das Handeln im Raum haben (1978: 190). Die funktionelle Ähnlichkeit, aber auch die Unterschiede der ,Angebote“ von Raumstrukturen und Objekten einerseits und von Zeichen andererseits kehrt im Hinweis-Ansatz in der Unterscheidung von Lesbarkeits- und Benutzbarkeitshinweisen wieder (s. dazu Hausendorf/Kesselheim 2016). - Eine ähnliche Gleichsetzung von Kommunikation und der Auswertung von affordances findet sich bei dem Techniksoziologen Ian Hutchby, wenn er das Funktionieren der affordances mit Hilfe der Analogie zum Funktionieren von Paarsequenzen im Gespräch erklärt: So, wie eine Einladung die Interpretation der Folgeäußerungen beschränke (die als Annahme, Ablehnung oder als Ausweichen gehört würden), so stellten die affordances eines Objekts die Rahmenbedingungen für dessen Interpretation und den Möglichkeiten des Handelns ihm gegenüber zur Verfügung (Hutchby 2001: 446-453).

6 Hinweise darauf, in welcher Richtung ein solcher Weg zu suchen ist, gibt meines Wissens lediglich der Designtheoretiker Norman (1988), der eine Reihe von Quellen für die Erschließung der affordances eines (menschengemachten) Objekts anführt: und zwar den sichtbaren Aufbau des Objekts, den (wiedererkennbaren) Rückgriff auf kulturelle Standards, auf allgemeine Prinzipien der menschlichen Wahrnehmung oder auf Vorwissen über den betreffenden Gegenstand und seine Verwendung (s. besonders Norman 1988: 23ff.).
} 
ihrer räumlichen Umwelt die Besucher als Erscheinungsformen der Kommunikation durch die Ausstellung für ihre Kommunikation in der Ausstellung nutzen.

Das Hinweis-Konzept setzt also die Versuche fort, im Rahmen der Konversationsanalyse die Nutzung der räumlichen Umwelt und der in ihr vorgefundenen Dinge zu bestimmen, geht aber über diese Versuche hinaus, indem es eine detailliertere Rekonstruktion der Art und Weise gestattet, wie die Bedeutungspotenziale der „material structure in the environment“ in die Interaktion integriert werden. Dabei bleibt die konversationsanalytische Vorstellung von der interaktiven Konstruktion des Raums (Kapitel4) unangetastet, aber zugleich kann genauer beschrieben werden, woran genau diese interaktive Konstruktion an dem im Raum Vorgefundenen ansetzt und wie es kommt, dass viele Besucher den Ausstellungsraum auf ähnliche Weise konstruieren und nutzen: Das Hinweis-Konzept geht eben davon aus, dass die Besucher die Bedeutung des Ausstellungsraums und des in ihm Vorgefundenen im Verlauf ihrer Interaktion konstruieren, indem sie Hinweise in ihrer räumlichen Umwelt auswerten, ${ }^{7}$ die ein bestimmtes Verständnis, eine bestimmte Nutzung des Raums und seiner Objekte erwartbar machen.

Das Hinweis-Konzept ermöglicht einen dritten analytischen ,Schub‘, in dem nicht mehr nur die Kommunikation durch die Ausstellung oder die Kommunikation in der Ausstellung in den Blick genommen wird, sondern deren Zusammenspiel. Mit anderen Worten: Es ermöglicht zu untersuchen, wie die Besucher das komplexe semiotische Arrangement im Ausstellungsraum für ihre in Kapitel 5 rekonstruierte soziale Praxis des gemeinsamen Museumsbesuchs nutzen. Dabei kommt es mir nicht darauf an zu beweisen, dass die Besucher tatsächlich diejenigen Hinweise (und nur die Hinweise) nutzen, die in Kapitel 3 rekonstruiert worden sind. In der Tat werden wir auch sehen, dass das Verhalten der Interaktionsbeteiligten an anderen als den rekonstruierten Hinweisen anknüpfen kann und welche Folgen dies für das untersuchte Interaktionsereignis haben kann. Wichtiger sind die prinzipiellen Einsichten, die sich aus der Analyse für die Frage gewinnen lassen, wie Menschen in ihrer Interaktion mit dem umgehen, was sie in ihrer räumlichen Umwelt vorfinden. Damit weisen die Analysen dieses Kapitels über den Fall der Ausstellungskommunikation hinaus.

7 Wichtig ist zu bemerken, dass das Hinweis-Konzept keinerlei Aussagen darüber trifft, wie sich die Auswertung der Hinweise im Innern der Besucher vollzieht: ob also die Besucher die Bedeutung einzelner Hinweise ,addieren' oder ob sie in ihrer Umwelt Hinweise in einer Art holistischer Gestaltwahrnehmung entdecken, ob es nur um Wahrnehmungen geht oder auch um leibliche Erfahrungen. Das Hinweis-Konzept ist kein individualpsychologischer Ansatz, sondern versucht, Kommunikation ausgehend von den Phänomenen der kommunikativen ,Oberfläche‘ $\mathrm{zu}$ verstehen. 
Um die Nutzung von Hinweisen im Zuge des gemeinsamen Museumsbesuchs nachzuweisen, braucht man im Prinzip keine neuen Fälle zu untersuchen. Wenn die Nutzung des Ausstellungsraums durch die Besucher wirklich auf der Auswertung von Hinweisen im Raum basiert, dann müssten sich in den Videoausschnitten, die in Kapitel 5 untersucht worden sind, immer wieder auch Momente dieser Nutzung nachweisen lassen. In der Folge werde ich deshalb auf einige Ausschnitte zurückkommen, die ich schon in Kapitel 5 untersucht habe. Hinzu kommen einige neue Ausschnitte, in denen der Rückgriff auf die Hinweise entweder besonders gut zutage tritt oder die für die Analyse nach dem Hinweis-Ansatz besondere Probleme aufwerfen.

\subsection{Hinweis-Analyse: Ein einfacher Fall}

Anhand eines längeren Videoausschnitts, den ich bereits in Kapitel 1 herangezogen habe, um in den Gegenstand Ausstellungskommunikation einzuführen (V2910, „Zaunkönig“), möchte ich nun der Frage nachgehen, wie das HinweisKonzept ein besseres Verständnis der Art und Weise ermöglicht, wie Besucher das kommunikative Angebot im Ausstellungsraum für ihre Interaktion nutzen. In dem Ausschnitt sieht man wieder „Manfred“ (MA), „Ännie“ (苂) und deren erwachsene Tochter „Jeanette“ (JE), die sich gemeinsam mit einer Vitrine mit einheimischen Vögeln beschäftigen. Die Analyse konzentriert sich auf die Frage, wie die drei Besucher in ihrer Interaktion vor der Vitrine auf Hinweise im Ausstellungsraum zurückgreifen und wie sie sich diesen Rückgriff gegenseitig signalisieren.

\section{V2910, „Zaunkönig“ \\ $1 \quad(0.6) \#(1.0) \#$ \\ \#1 \#2}

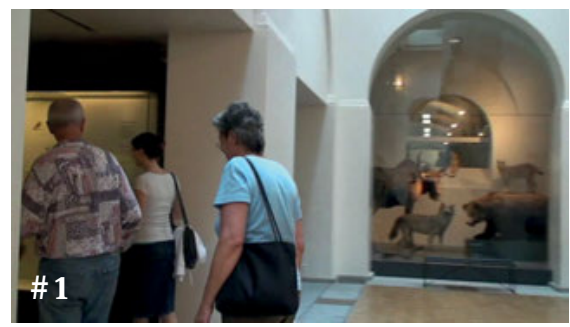

2 JE: \#DA, ZUUNchönig.\#

\#3

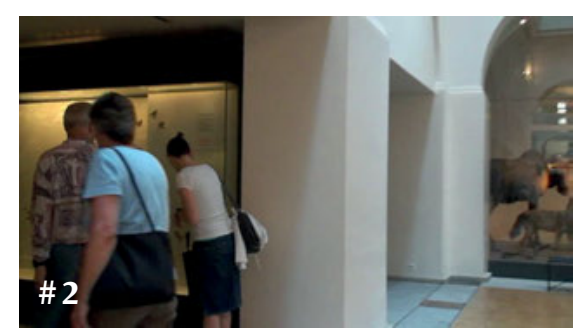



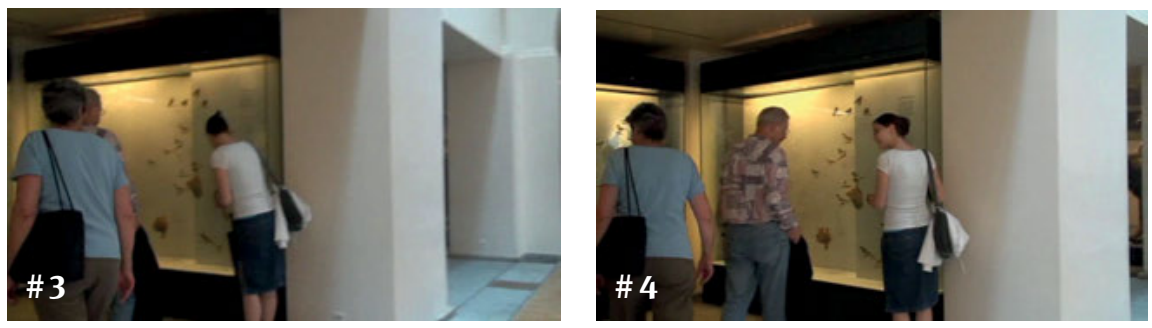

3 MA: $\langle<p>$ (dä ZUUNchönig); >

4 (---)\# CHUMM änni. (.) \#

\# 5

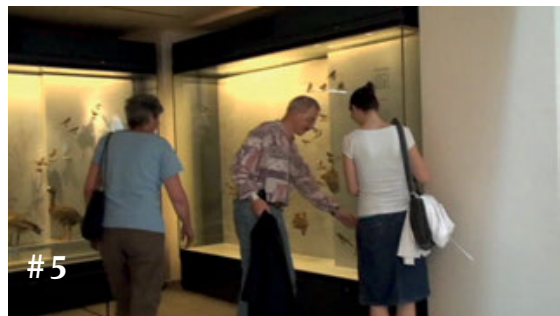

5 ÄN : dEr ZAUNkönig. (0.5)\#

\section{\#7}

$6 \quad(4.5) \quad($ Vogelzwitschern) $) \quad(2.0) \#$
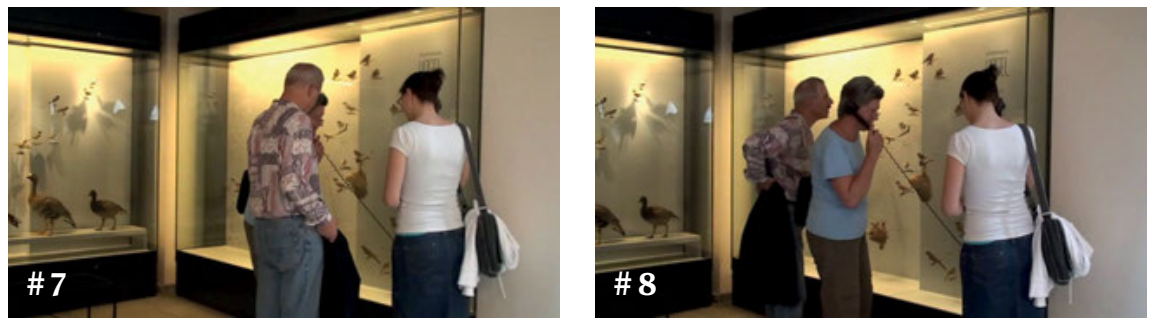

7 ÄN: das isch wAhnsinnig steRIL;

$8 \quad(-)$

9 MA: jA ä? wu_ISCH_är do.

10 (1.5)

11 \#ich suche su[che. \# 9

12 ÄN: [tsik tsik tsik TSIK,

13 =jetzt macht er wider DRRRRs.

$14 \mathrm{MA}$ : \#<<p, len>de BIRkenzeisig.>

$\# 10$ 

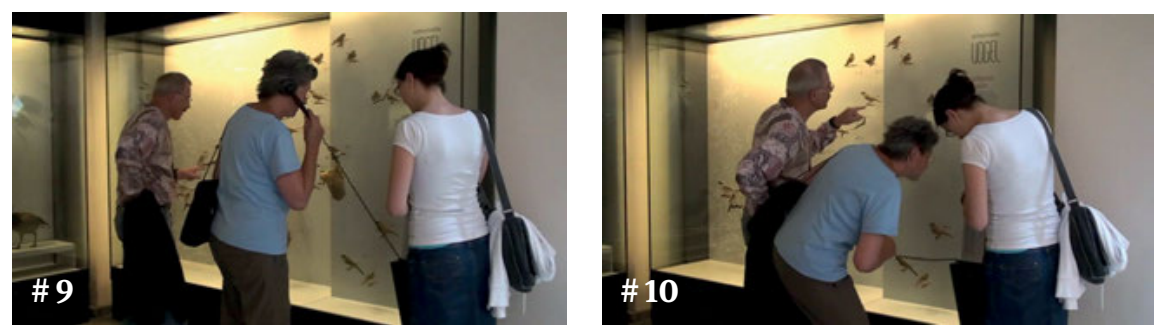

15 wo ISCH är denn; <<Standard>wo ! IS!ser (denn); >

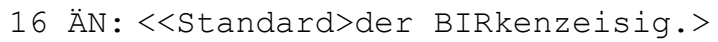

$17 \quad \#[=! \mathrm{DA} !$.

18 MA: \#[!NÄ̈̈! . =de ZUUNchönig.

\# 11

$19 \quad(3.0)$

$20 \mathrm{JE}:($ (gluckst)) \#

\section{\#11b}
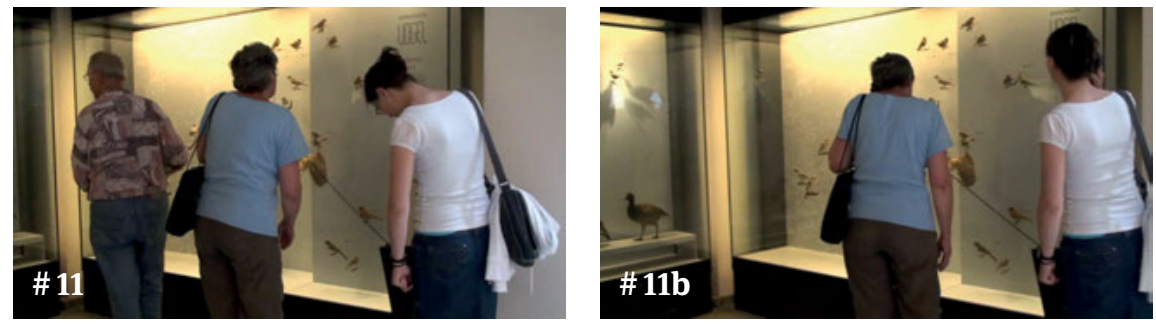

\section{1 (3.0)}

22 \#s hent die mEga cool gMACHT; \# \# 12

\section{\# 13}
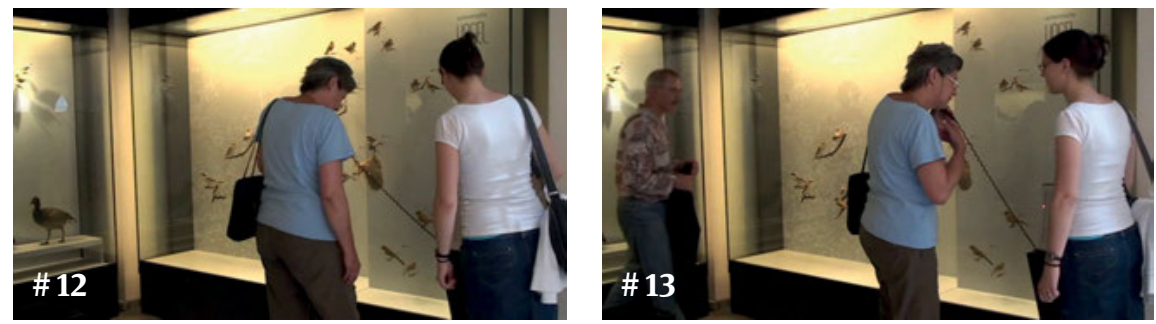

23 ÄN: (du/und) den überLOsisch ja fascht; (---)

$24 \mathrm{JE}$ : lUEg dä KLAPpergras

25 ÄN: \#und des \#is en (CHLIner) ( ). \#14 \#14b 

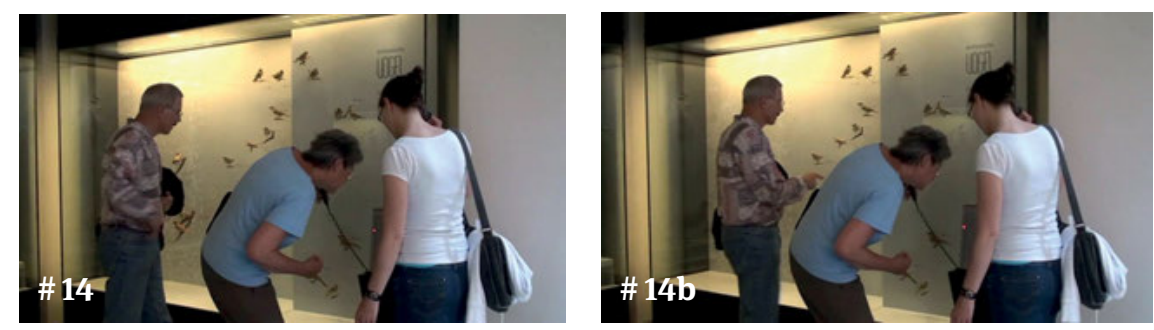

26 JE: DA. (-)

27 BEUtelmeise.

28 ÄN: \#<<p>die bEUtelmeise $>$ isch DÄ da. $\# 15$

$29(---) \# \quad(3.0) \# \quad(2.1)$

$$
\# 16 \quad \# 17
$$

30 MA: <<liest>EINheimischer; >

$31 \quad(--)$ \#

$$
\text { \#18 }
$$
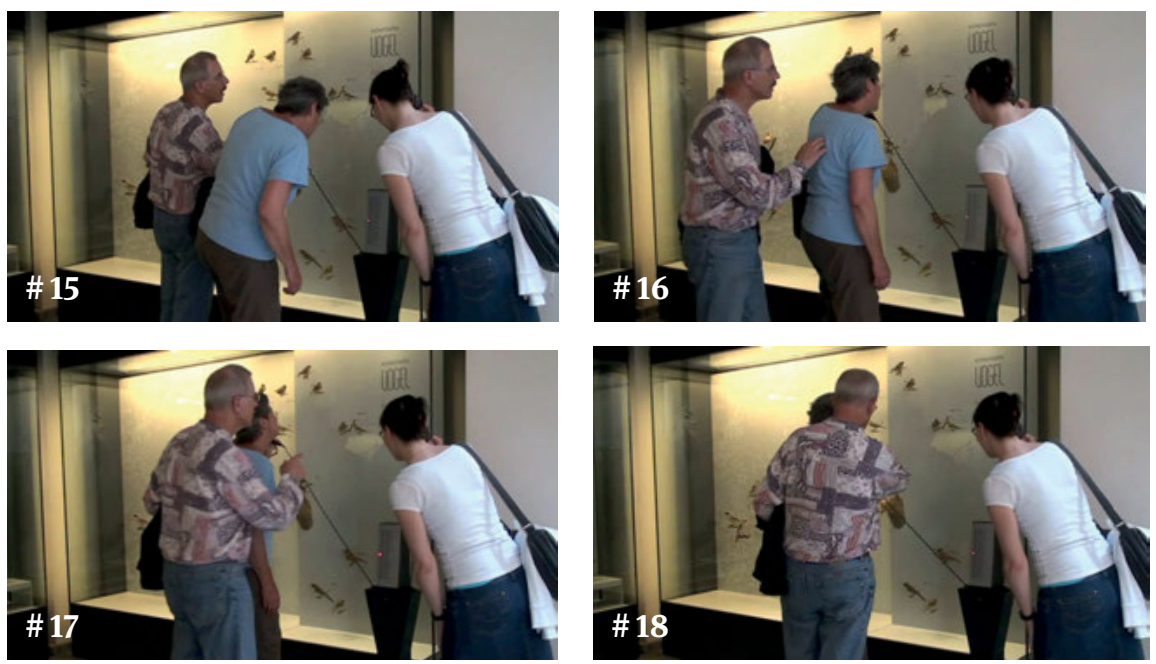

$32<<$ haucht>das isch> en IIheimischä [VoGgel.
33 JE:
[ JOHA! ,

34 aber so sëlte.

35 ÄN: (xxx) (jetzt wider) TS_SCH: : : (wie die) [ ( )

$36 \mathrm{JE}:$

[ich han

das

37 (megaCOOL) [gfunde;

38 MA: $\quad[<<e r s t a u n t>$ häsch du das [gWÜSST,

$39 \mathrm{X}: \quad$ [JA, 
$40 \mathrm{JE}: \mathrm{WAS},=\#$

\section{\#19}

41 MA: =dass das en IIheimische VoGgel isch.>

$42 \mathrm{JE}:(\operatorname{xxx} \mathrm{xxx})$ [((lacht))

43 ÄN : $\quad[(x x x$ xxx $)<<$ Standard>die MEIse; $>\#$

\#20
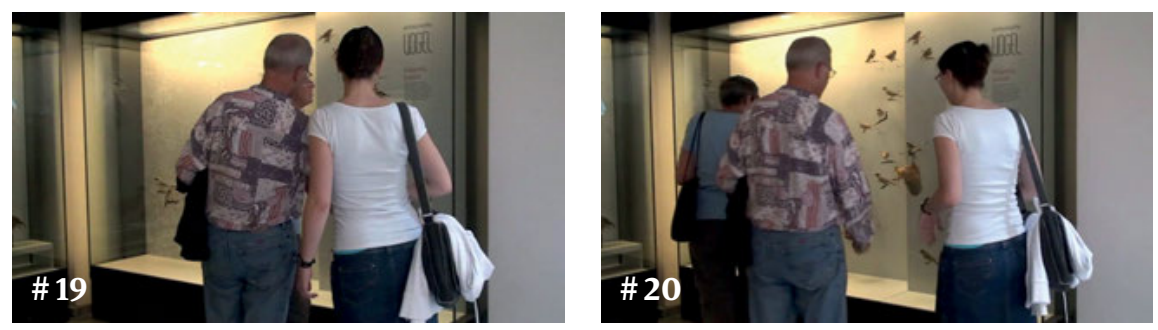

hier) de VoGgel. (hier/ja)

45 MA: DAS da isch es \#[NESCHT.

46 ÄN :

\# [DAS-

\#21

47 MA: han i no NIE gsehn.

$48 \mathrm{JE}:<<$ erstaunt>NÖD.>

49 MA: <<behaucht $>$ NEI. $>$
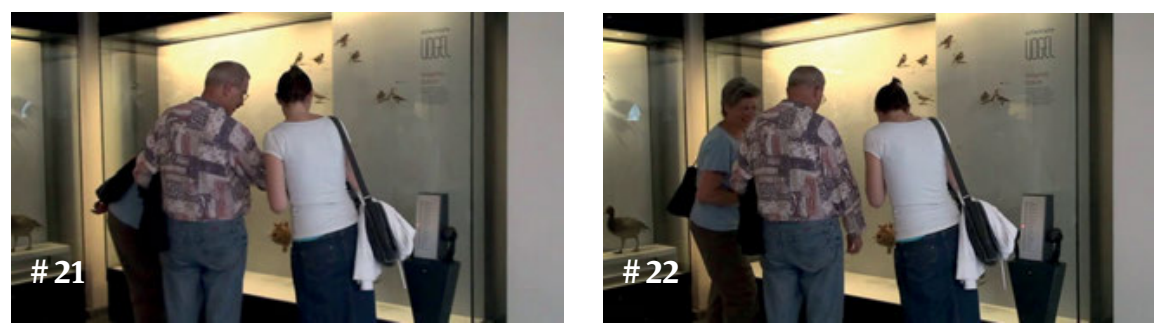

$50 \quad(---)$

$51 \mathrm{JE}: j a$ wenn sie (nöd $\mathrm{xxx} \mathrm{xxx}$ )

52 ÄN: MEIN ZAUNchönig.\#

\#22

$53 \quad \# \mathrm{HÄ}$ ?

\#23

54 MA: d:̈ da han_i gSUECHT-

55 und da macht är sElles NESCHT.\# 

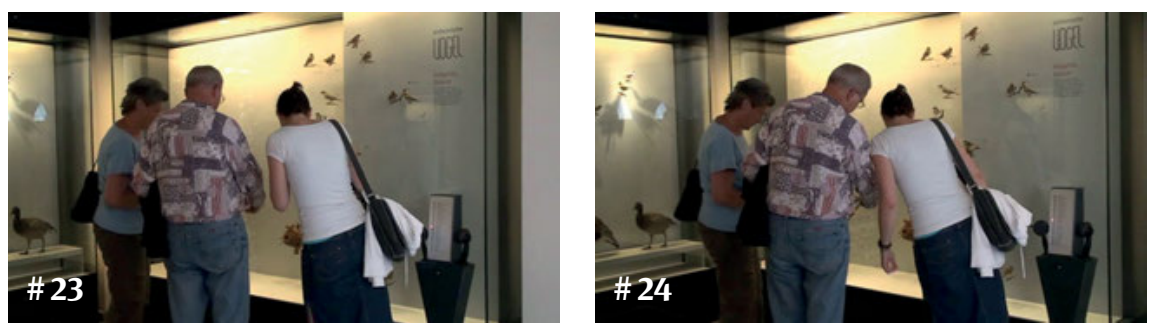

56 JE: trogloDytes trogloDytes;

57 ÄN : $m H m$ ?

58 MA: ( (haucht))

59 ÄN: (xxx \#DÄNK s isch [scho_nes HERzigs [vÖgeli \#25

$60 \mathrm{MA}:$

[ ( ) (no mal),

$61 \mathrm{JE}:$

[trogloDYtes

62 troglodDytes. (-)

63 ÄN: SCHWARZ\#specht.

\#26

$64 \quad(3.0)$

$65 \mathrm{MA}:(\quad)(2.0) \#$

\#27
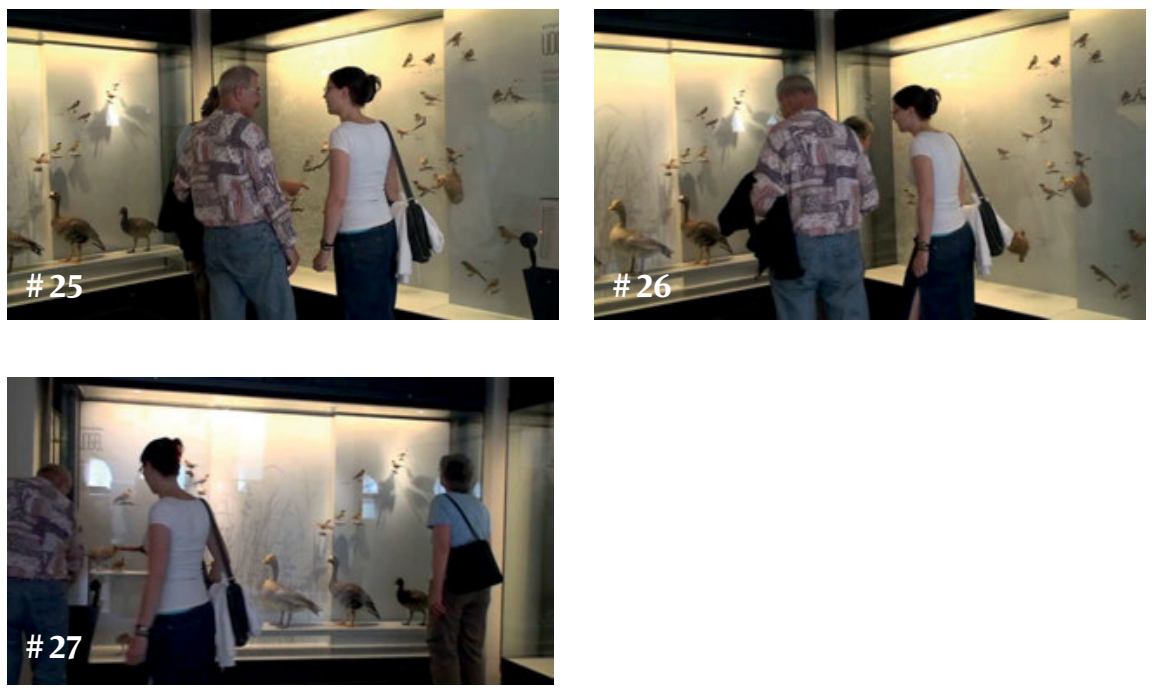

Mit Einsetzen des Transkripts verlassen Manfred, Ännie und Jeanette die offene Ausstellungshalle im Erdgeschoss des Zoologischen Museums und betreten einen 
niedrigeren Gang, der durch ein Spalier von Vitrinen zum Thema einheimische Vögel gebildet wird.

Abb. 6-1 a dokumentiert den Eingangsbereich dieses Gangs und die Vitrine, mit der sich die Dreiergruppe in der Folge beschäftigt.

Abb. 6-1 b zeigt den Vitrinengang aus einer anderen Perspektive (die Zaunkönig-Vitrine wird hier durch die weiße Säule vorne rechts verdeckt). Wenn die Besucher zu Beginn des transkribierten Ausschnitts vor der Vitrine stehen bleiben (\#3 bis \#7), lässt sich der Ort ihres Stehenbleibens auf eine ganze Reihe von Hinweisen im Ausstellungsraum beziehen, die genau dieses Stehenbleiben wahrscheinlich und im Rahmen des gemeinsamen Museumsbesuchs sinnvoll machen.

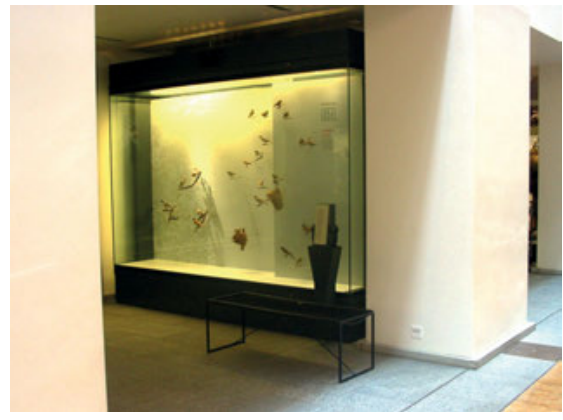

Abb. 6-1a

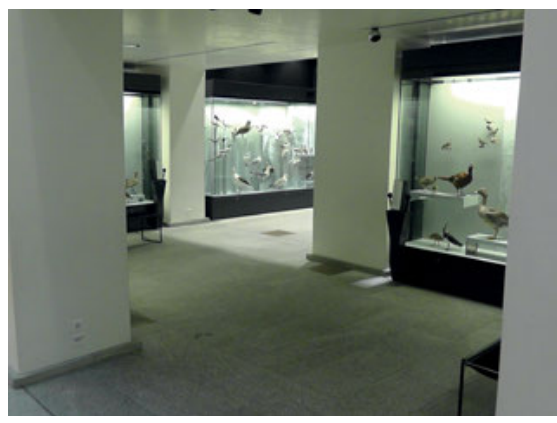

Abb. 6-1b

Die Dreiergruppe bleibt nicht in der Mitte des Gangs stehen, von dessen langgestreckter Form der Hinweis ausgeht ,Weitergehen!' (zu diesen und den folgenden analytischen Beobachtungen s.o., 3.3). Blieben die drei Besucher dort stehen, hieße das, den Fluss von (potenziellen) Besuchern zu blockieren, der durch diesen Hinweis erwartbar gemacht wird. Stattdessen halten sie in einem Bereich an, in dem mehrere Hinweise zugleich suggerieren, dass ein Stehenbleiben nicht nur möglich, sondern in vielerlei Hinsicht lohnend ist. Der Bereich unmittelbar vor der Vitrine ist deutlich von der ,Ideallinie“ entfernt, die ein schnelles Durchschreiten des Vitrinengangs ermöglichte; dies kann als Hinweis darauf verstanden werden, dass der Bereich vor der Vitrine keine ,Gehzone“ ist. Den gleichen Hinweis gibt das kleine Bänkchen, das sich einem Durchqueren des Bereichs vor der Vitrine entgegenstellt. Gleichzeitig suggeriert es, dass es an dieser Stelle lohnend sein kann, länger zu verweilen, und zwar indem es eine Möglichkeit anbietet, sich hinzusetzen. Wenn nun die Familie in einem Bereich stehen bleibt, der durch diese Hinweise als zum Stehenbleiben einladend ausgewiesen ist, fällt es schwer, dieses Verhalten nicht auf die Hinweise im Raum zu 
beziehen und es nicht als ,Anhalten in einer Verweilzone‘ zu beschreiben. Anders formuliert: Dass die Gruppe hier ohne auffällige Abstimmungsaktivitäten genau hier stehen bleibt, kann man gut mit den rekonstruierten Benutzbarkeitshinweisen erklären, die genau dieses Verhalten hochgradig erwartbar und gleichzeitig interaktiv wirksam machen. Unabhängig davon, warum die Gruppe ,tatsächlich“ hier verweilt, ihr Verweilen kann als Reaktion auf einen Verweilhinweis in der Ausstellungsarchitektur verstanden werden und setzt diesen zugleich interaktiv relevant.

Damit ist die Position des Stehenbleibens allerdings noch nicht ausreichend beschrieben. Speziell Jeanettes Position im Raum erfolgt an einer Stelle, die sich sichtbar dafür eignet, die Lesbarkeits- und Benutzbarkeitshinweise, die von der Audiostation rechts vorne an der Vitrine ausgehen, maximal auszuschöpfen (Abb. 6-2). Ihre Position muss als ,bei der Audiostation' angegeben werden. So lässt sich die Länge der Kabel, die die Hörer mit der Audiostation verbinden, als Hinweis auf die Standpunkte auswerten, die als Benutzungspositionen verstehbar sind. Entsprechendes gilt für die Knöpfe und die Größe der Schrift auf dem Bedienfeld, woraus sich ein Hinweis auf potenzielle Nutzungspositionen gewinnen lässt: Positionen nämlich, von denen aus die Schrift entziffert und die Knöpfe gedrückt werden können. Wenn Jeanette nun in geringem Abstand vor der Audiostation stehen bleibt, also an einem Standpunkt, der es ihr erlaubt, Hörer und Bedienfeld der Audiostation zu manipulieren, und wenn sie sich zusätzlich nach vorne beugt, was ein Lesen erleichtert (\#2, \#3), dann ist es schwer, ihre Position nicht mit Bezug auf die Audiostation als ein ,Anhalten vor der Audiostation‘ zu sehen.

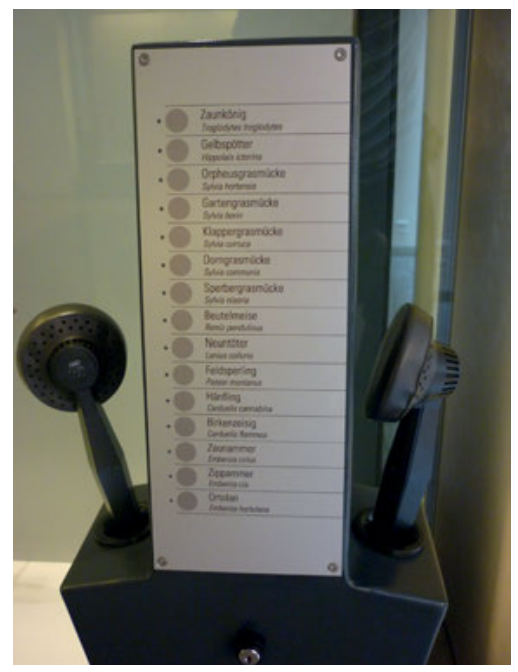

Abb. 6-2 
In der Folge signalisieren sich Jeanette und ihre Begleiter auf vielfältige Weise, dass sich ihr räumliches Verhalten auf diese von der Audiostation nahegelegten Nutzungsmöglichkeiten bezieht. So integrieren sie die im Ausstellungsraum vorgefundene Audiostation in ihre lokal hervorgebrachte Interaktion.

- Jeanette, die als erste die Audiostation erreicht hat, macht für die anderen ihre Nutzung der Bedientafel im Sinne der eben beschriebenen Hinweise kenntlich, indem sie neben der Hörstation stehen bleibt, sich vorbeugt und dabei laut „DA, ZUUNchönig.“ äußert. Am Ende der Äußerung wendet sie den Kopf zu Manfred, den sie damit als Zuhörer auswählt, aber mit dem Becken bleibt sie weiterhin auf die Audiostation orientiert (vgl. den Übergang von \#3 zu \#4).

- Manfred signalisiert zunächst, dass er Jeanettes Orientierung an der Audiostation übernehmen wird: Er greift nach dem Hörer, wobei er sich so stellt, dass er mit Jeanette ein , $\mathrm{V}^{\star}$ bildet, dessen Schenkel die Audiostation gleichsam umschließen (\#5). Anstatt aber den Hörer an das Ohr zu halten, gibt er ihn an seine Frau Ännie weiter.

- Wie schon Jeanette, hält sich nun auch Ännie den Hörer ans Ohr (\#6, \#7), womit die beiden Frauen einen Benutzbarkeitshinweis auswerten, der sich aus ihrer Vertrautheit mit Geräten dieser Art speist, nämlich dass Hörer als Angebote zu verstehen sind, mit ihrer Hilfe etwas zu hören. Mit ihrer Position bilden sie wieder das zuvor beschriebene , $V^{`}$. Durch diese Position und ihre gesenkte Kopfhaltung machen sie sichtbar, dass ihre Aufmerksamkeit der Audiostation gilt. Diese Aufmerksamkeit hat zwei Aspekte. Einerseits gilt sie dem Lesen der Schrift und dem Bedienen der Knöpfe auf der Vorderseite der Audiostation, was Ännie und Jeanette durch auffällige ,Verbiegungen“ des Körpers sichtbar werden lassen (Ännie: \#10, \#14; Jeanette: \#11). Andererseits ist sie auf die Nutzung der Hörer zum Abhören der Vogelstimmen gerichtet (was Ännie durch ihre Nachahmung der Vogellaute, Z. 12, oder ihre deiktische Bezugnahme auf die Geräusche und ihre Erzeuger hörbar macht: „das isch wAhnsinnig steRIL“, Z. 7; ,jetzt macht er wider DRRRRs“, Z. 13). - Dass auch das Halten der Hörer die Funktion hat, diese Nutzung der Audiostation sichtbar zu machen, wird besonders dann sichtbar, wenn Ännie den Hörer in der Hand behält, auch wenn sie ihn gerade nicht zum Hören nutzt, sondern auf dem Bedienfeld die Schrift „Birkenzeisig“ sucht (Z. 10).

Die beiden Frauen zeigen also durch ihre sichtbare und hörbare Ausrichtung auf die Hinweise sich gegenseitig (aber auch ihrem Begleiter Manfred, der Ännie anfangs bei ihrem Hören der Vogellaute beobachtet, \#7), dass die Audiostation ein Element der räumlichen Umwelt ist, das herangezogen werden muss, wenn man ihre Interaktion verstehen will. 
Besonders interessant ist in diesem Hinblick die Positionierung von Jeanette und Ännie, die gleichzeitig als ,bei der Audiostation“ und als ,vor der Vitrine“ beschrieben werden kann, weil von ihrer Position aus sowohl die Hinweise der Audiostation genutzt werden können als auch solche, die an und in der Vitrine entdeckt werden können. Insbesondere machen sie sichtbar, dass sie eine Reihe von Verknüpfungshinweisen auswerten, die die Audiostation und die Vitrinen mit ihren Exponaten miteinander verknüpfen (s.o. 3.5) und die sich an dieser Stelle gleichsam ,aufdrängen‘. Zu diesen Hinweisen zählen

- die Nähe von Audiostation und Vitrine,

- die Ausrichtung der Vorderseiten von Vitrine und Bedientafel, die die gleichzeitige Rezeption bzw. Nutzung von ein und demselben Standpunkt aus ermöglicht, oder

- das Vorkommen der gleichen Tiernamen auf dem Bedienfeld der Audiostation und auf den Objektkennungen in der Vitrine.

Die Auswertung dieser Hinweise zeigen sich Ännie und Jeanette durch ihre Position zwischen Vitrine und Audiostation an sowie dadurch, dass sie beim Anhören einer Vogelstimme an der Audiostation mit den Blicken nach dem entsprechenden Exponat in der Vitrine suchen. Auch die Tatsache, dass sie in ihren Gesprächsbeiträgen wie selbstverständlich davon ausgehen, dass nach dem Drücken eines Knopfs diejenige Vogelart zu hören ist, deren Namen rechts neben dem Knopf aufgeführt ist (s. wieder Abb. 6-2), zeigt, dass sie die Nähe von Schrift und (unbeschriftetem) Knopf als Verknüpfungshinweis ausgewertet haben. Wieder lässt sich also das räumliche Verhalten der Interaktionspartner als ein Aktivieren von Hinweisen im Raum (und die Verdeutlichung dieser Aktivierung für ihre Interaktionspartner) verstehen.

Wenn bisher davon die Rede war, die Gruppe stehe ,vor der Vitrine‘, dann fehlt noch ein wichtiges Element zur Beschreibung ihrer Position im Raum: die Relevanz des Vitrineninneren. In Kapitel 3 habe ich eine Reihe von Hinweisen rekonstruiert, mit denen die Vitrinen die genaue Betrachtung der Gegenstände in ihrem Innern hochgradig wahrscheinlich machen (s.o. 3.3 und 3.6):

- Die gläserne Hülle und die autonome Innenbeleuchtung der Vitrine maximieren die Sichtbarkeit des Vitrineninneren und signalisieren so die Bedeutsamkeit des In-die-Vitrine-Sehens. Diese Hinweise machen aus der Verweilzone vor der Vitrine, wie wir gesehen haben eine auf die Exponate im Vitrineninneren gerichtete Betrachtungszone.

- Die breite Glasfläche gestattet es, die Dinge im Innern von einer großen Zahl unterschiedlicher Positionen aus betrachten. Dies kann als Hinweis darauf verstanden werden, dass dem einzelnen Betrachter möglichst viele alternative Perspektiven ermöglicht werden sollen, oder aber als Hinweis darauf, 
dass die Vitrine von mehreren Personen gleichzeitig genutzt werden kann und soll. Allerdings gibt die Vogelvitrine den Blick nur von einer Seite aus frei, die dadurch zur Vorderseite wird (und nur hier findet man die oben erwähnte Verweil- und Betrachtungszone).

- Des Weiteren gibt es Hinweise darauf, dass der Blick nicht dem gesamten Vitrineninnern gelten soll, sondern den dort arrangierten Objekten: Diese sind so platziert, dass sie der Höhe der Augen entgegen gehoben sind; das gibt den spezifischeren Hinweis, dass diese Objekte von Nahem, also mit Aufmerksamkeit auf ihre Details, betrachtet werden sollen. Dazu passt, dass die Vitrine nur eine geringe Tiefe aufweist, sodass alle Objekte trotz der trennenden Glaswand aus unmittelbarer Nähe betrachtet werden können und, so die Botschaft dieses Arrangements, sollen. Schließlich kann der große Abstand zwischen den Objekten und die unterschiedliche Höhe ihrer Anbringung als Hinweis gelesen werden, dass es hier um die Sicherstellung der optimalen Sicht auf diese Objekte geht: dieses Arrangement der Objekte verhindert, dass sie sich gegenseitig verdecken, wenn man sie von verschiedenen Punkten der Betrachtungszone aus anschaut.

Die drei Besucher zeigen sich nun gegenseitig an, dass sie die Vitrine in genau diesem von den Hinweisen suggerierten Sinn nutzen:

- Sie bleiben dort stehen, wo die Vitrine ihre Vorderseite signalisiert, richten ihre Körpervorderseite auf die Vitrine aus und schauen in ihr Inneres. So wird ihr Stehenbleiben verstehbar als ein ,Stehenbleiben, um in der Vitrine etwas betrachten zu können'.

- Ihre Blicke und Zeigegesten sind oft auf die Objekte ausgerichtet (klare Fälle sind beispielsweise Ännie in \#10, \#11, \#13b, \#14, \#14b, \#15, \#27, Manfred in \#8, \#9, \#10, \#14b, alle drei in \#21, \#23, \#24).

- Dass sie die Objekte in der Vitrine als Betrachtungsgegenstände nutzen, machen sie sich durch auffällige Bewegungen deutlich: Manfred bückt sich, nähert sein Gesicht, um das Zaunkönig-Exponat besser sehen zu können, schiebt den Oberkörper weit nach vorne (\#8, \#15), Jeanette beugt sich deutlich nach vorne (\#22 bis \#24) usw.

- Den Bezug auf die Exponate verdeutlichen sie sich auch sprachlich: etwa durch die Verwendung von Demonstrativpronomina (,die bEUtelmeise isch $D \ddot{A}$ da.“, Z. 28) oder mittels Adverbien wie da (,DA. ZUUNchönig.“, Z. 1) oder selles (,solch ein‘, in „sElles NESCHT“, Z. 55). Auch fordern sie sich explizit auf, einzelne Präparate anzuschauen: „lUEg dä KLAPpergras“ (Jeanette in Z. 25) oder kommentieren ihre Aktivität explizit als Suche nach einem Exponat, wie etwa Manfred zu Beginn des Transkriptionsausschnitts: „wu_ISCH_är do. (1.5) ich SUche SUche.“ (Z. 10f.). 
- Und schließlich zeigt Manfred an, dass seine Position vor der Vitrine sich aus der visuellen Orientierung auf die Exponate ergibt, indem er seine Frau Ännie zur Seite schiebt, die seinen Blick auf die Vogelpräparate rechts in der Vitrine verdeckt (\#16), oder indem er hinter ihr herum geht, was für ihn einen deutlichen Umweg bedeutet, aber ihren Blick auf die Exponate nicht verdeckt (vgl. seinen Weg von \#15 zu \#18).

Mit ihrer Nutzung der Objekte in der Vitrine zeigen die drei Besucher ihre Orientierung an den zahlreichen Hinweisen im Ausstellungsraum, die keinen Zweifel daran lassen, dass es sich hier nicht um einfache, in der Vitrine aufbewahrte Gegenstände handelt, sondern dass es sich um ausgestellte Objekte handelt, die im Rahmen der Ausstellungskommunikation als Zeichen fungieren. Diese Nutzung der Dinge im Innern der Vitrine als Zeichen wird offenbar, wenn die Besucher auf die Exponate in ihrem gemeinsamen Wahrnehmungsraum referieren, aber gleichzeitig Aussagen treffen über eine Klasse von Lebewesen (die Gattung oder Art, die sie als von dem Objekt repräsentiert verstehen):

- Wenn Manfred im Angesicht des Zaunkönigexponats sagt „dÄ da han_i gSUECHT- und da macht är sElles NESCHT.“ (Z. 54f.), geht er höchstwahrscheinlich nicht davon aus, dass das leblose Präparat in der Vitrine dieses Nest gemacht hat, sondern ein lebender Vertreter der Gattung.

- Auch kann sich Ännies Behauptung, die Beutelmeise sei selten („SO sÄlte“, Z. 34), nicht auf das Beutelmeisenexponat beziehen, das die drei Besucher sehen können: Es gibt nicht weniger Beutelmeisenpräparate in der Vitrine als etwa Zaunkönigpräparate. Die Behauptung bezieht sich vielmehr auf die Beutelmeise als Art und ihr Vorkommen in der freien Wildbahn.

Dass die Besucher Elemente in ihrer räumlichen Umwelt als Bestandteile eines kommunikativen Angebots auffassen, wird besonders deutlich, wenn die Besucher etwas im Raum lesen - stärker noch als wenn sie, wie soeben beschrieben, Exponate als Zeichen behandeln. Da das Lesen im Prinzip keine sicht- oder hörbare Reaktion, sondern lediglich stille Interpretationsvorgänge erforderlich macht, müsste es schwer, wenn nicht unmöglich sein, Lesen im Ausstellungsraum zu beobachten. Dass man das Lesen in meinem Korpus dennoch häufig beobachten kann, liegt daran, dass sich die Besucher gegenseitig signalisieren, dass sie Lesbarkeitshinweise auswerten, die sie aus Texten im Ausstellungsraum gewinnen.

Stilles Lesen zeigen sie sich beispielsweise durch eine auffällige Kopfhaltung an: ein starkes Nach-vorne-Recken, ein Abknicken nach unten oder ein Schiefhalten, parallel zur Ausrichtung der Schriftzeilen auf dem betreffenden Textträger (vgl. Ännie in \#10, \#14, \#14b, \#19). Diese Haltung erlaubt zu sehen, dass sie trotz ihres manchmal ausgedehnten Schweigens bei der Lektüre immer 
noch am gemeinsamen Museumsbesuch teilnehmen. Das klarste Signal, mit dem die Besucher sich anzeigen, dass sie etwas im Ausstellungsraum als Schrift verstehen und nutzen, ist aber das laute Lesen. Das laute Lesen ist eine Methode, innere Vorgänge in die Interaktion ,einzuspeisen', den anderen zu vermitteln, mit welcher Textstelle genau man sich im Moment beschäftigt, welche Informationen man gerade verarbeitet. Es erlaubt aber auch, den eigenen Redebeitrag mit der Autorität der Museumsexperten zu versehen (s.o. 3.2.5). Wie wichtig es den Besuchern ist, kenntlich zu machen, dass sie mit einer Äußerung etwas an oder in der Vitrine Gelesenes wiedergeben, kann man daran ermessen, dass sie das Lesen in aller Regel mit mehreren Mitteln zugleich erfahrbar machen. Dies lässt sich auch in dem „Zaunkönig“-Ausschnitt illustrieren:

- Es wird nicht bloß laut gelesen, es wird auch per Körperhaltung (ein Vorbeugen) und Deixis angezeigt, wo sich das Gelesene im Wahrnehmungsraum befindet: „DA, ZUUNchönig“ (Jeanette in Z. 2).

- Es wird nicht bloß laut gelesen, sondern das Lesen wird mit einer speziellen, wiedererkennbaren Vorleseintonation verdeutlicht.

- Es wird nicht bloß laut gelesen, sondern das Lesen durch ein Code-Switching vom Schweizerdeutschen zum Standarddeutschen zusätzlich deutlich gemacht (Manfred: „EINheimischer;“, Z. 30; Ännie: „der BIRkenzeisig.“, Z. 16).

Unmerklich sind wir im Laufe der Analyse von Hinweisen, die sich auf die Steuerung der Raumnutzung beziehen (wohin soll ich gehen, wo stehen bleiben, wohin blicken?) zu solchen Hinweisen übergegangen, die sich nur im Rahmen von Kommunikation finden lassen. Hier treffen wir ,alte Bekannte' der Textlinguistik wieder: beispielsweise Themahinweise (s. Hausendorf/Kesselheim 2008: 103-138 und 3.6) oder Hinweise auf Textfunktionen (ebd.: 139-169 und 3.7).

Wieder können wir sehen, wie die Besucher diese Hinweise im Raum für ihre Interaktion relevant setzen. So kann das Wort „Zaunkönig“ neben dem entsprechenden Play-Knopf auf dem Bedienfeld der Audiostation (s.o., Abb. 6-2, S. 459) - als Themahinweis verstanden werden: ,Hier geht es um den Zaunkönig!‘. Indem Jeanette „Da, ZUUNchönig.“ vorliest (Z. 2) und dann vor der Audiostation stehen bleibt, zeigt sie ihren Begleitern, dass sie gerade diesen Hinweis auswertet. Damit zeigt sie den Sinn ihres Stehenbleibens an - ein Stehenbleiben, das im Zusammenhang mit dem Zaunkönig steht - und legt gleichsam den Tenor der Beschäftigung mit der Vitrine fest: „Zaunkönig“ fungiert wird wie eine Art Überschrift, die die Erwartung begründet, womit sich die Gruppe im Anschluss beschäftigen wird.

Mit ihrer Äußerung setzt Jeanette ein Thema fort, das die Gruppe schon vorher etabliert hat und das als eine Art running gag ihren Museumsbesuch durchzogen 
hat: Schon in einer zuvor betrachteten Vogelvitrine und selbst in einer Reptilienvitrine hat Manfred nach dem Zaunkönig gesucht bzw. diese Suche spielerisch vorgegeben. Jeanettes „DA, ZUUNchönig.“ knüpft an diese Interaktionsgeschichte im Sinne eines Themabeibehaltungshinweises an, verbindet das Thema aber nun mit der konkreten Position im Raum (vgl. das deiktische „DA“ und ihre Körperhaltung in \#2 und \#3]). Mit anderen Worten: Jeanette signalisiert hier, dass es an ihrer Position im Raum etwas gibt, das geeignet ist, das in ihrer Interaktion aufgebrachte Thema Zaunkönig fortzuführen. Und genau so nutzen Jeanette und Ännie die Audiostation (\#7, \#8, \#9) und Manfred die Vitrine ${ }^{8}$ (Z. 9, vgl. Z. 11, und 15): Sie gewinnen aus dem multimodalen Arrangement an dieser Stelle des Raums Informationen zum Thema Zaunkönig (zu seiner Stimme, seinem Aussehen, seinem Nestbau).

Bei der anschließenden Nutzung der Vitrine entwickelt sich die Identifikation der Exponate in Begriffen der zoologischen Taxonomie zum dominierenden thematischen Zusammenhang („DA, ZUUNchönig.“, Z. 2; „der BIRkenzeisig. !DA!.“, Z. 16f.;,,da BEUtelmeise. <<p> die bEUtelmeise isch DÄ da.“, Z. 26-28). Unter allen möglichen Formen der Referenz auf die Objekte in der Vitrine wählen die Besucher gerade die, die zu der thematischen Orientierung passen, die durch Hinweise auf und in der Vitrine erwartbar gemacht werden, und zwar

- durch die Rekurrenz der Vogelnamen auf den Objektkennungen und dem Bedienfeld der Audiostation (in ihrer deutschen und ihrer lateinisch-griechischen Form),

- durch das Vorkommen von Wörtern aus einem gemeinsamen Wortfeld (den Oberbegriff „Vögel“ und „Vogelart“, „Revier-“, „Jugendkleid“) und schließlich

- durch die massive Präsenz von Exponaten, die als Vögel identifiziert werden können (und die dem Auge wenig mehr Informationen bieten als eben ihre Körpermerkmale, vgl. das fast völlige Fehlen von Elementen aus ihrem - nur im Vitrinentext beschriebenen - Habitat „Feldgehölz und Dickicht“).

Als Themahinweis wird des Weiteren die Vitrinenüberschrift „einheimische VÖGEL Feldgehölz, Dickicht“ genutzt, hörbar im folgenden Ausschnitt („Einheimischer Vogel“):

8 Wenn Manfred in der Vitrine nach ,seinem‘ Zaunkönig sucht, und nicht an der Audiostation, vor der Jeanette steht, wertet er ganz offensichtlich einen Verknüpfungshinweis aus, der darin besteht, dass die Audiostation direkt neben der Vitrine steht, s.o. 


\section{V2910, „Einheimischer Vogel“}

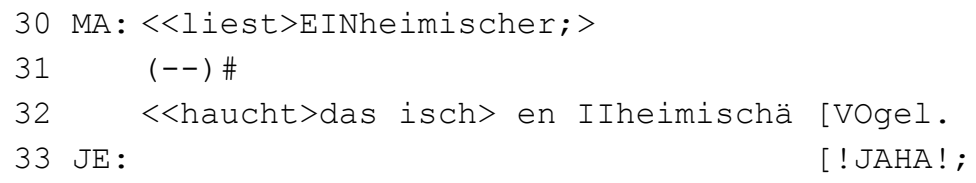

Die Überschrift „Einheimische VÖGEL“ findet sich auch auf den Vitrinen, die die Gruppe im Anschluss an die ,Zaunkönig-Vitrine‘ betrachtet. Diese Rekurrenz wird von der Dreiergruppe im Anschluss an den hier transkribierten Ausschnitt als Hinweis auf einen überspannenden thematischen Zusammenhang interpretiert, konkret: als Hinweis darauf, dass es sich bei den Exponaten in der Vitrine um einheimische Vogelarten handelt. ${ }^{9}$ Beide Themen, die Identifikation der Vogelpräparate nach ihren Arten und die Frage des Vorkommens in der Schweiz, sind in den Themahinweisen im Ausstellungsraum verankert.

Schließlich nutzen die Besucher die Vitrine auch im Sinn der Funktionshinweise, die eine Ausrichtung auf die lokale Konstruktion von zoologischem Fachwissen nahelegen. Ein Hinweis auf diese Funktion ist beispielsweise die Präsenz von Fachvokabular im Vitrinentext (s. Abb.1-2, S.7), in dem Büsche und Bäume als „Vertikalstrukturen“ bezeichnet werden und ihre Funktion als „Revierzentren“ beschrieben wird. Einen weiteren Hinweis gibt das massive Vorkommen lateinisch-griechischer Begriffe, in denen man die zweigliedrige zoologische Taxonomie erkennen kann. Beide Hinweise verweisen auf den gesellschaftlichen Funktionsbereich der Wissenschaft und spezifischer: auf die Zoologie als Fachdisziplin. Dass die Besucher Funktionshinweise nutzen, die eine Orientierung des Ausgestellten an der Vermittlung von Wissen anzeigen, geben sie sich beispielsweise dadurch zu erkennen,

- dass Manfred das im Vitrinentext Gelesene als Wissen thematisiert: "«<erstaunt>häsch du das gWÜSST, dass das en IIheimische VOGgel isch.>“ (Z. 38, 41) oder „DAS da isch es NESCHT. han i no NIE gsehn.“ (Z. 45, 47);

- oder daran, dass Jeanette mit ihrer Äußerung „troglodytes troglodytes“ auf ein spezialisiertes Fachwissen Bezug nimmt, das in einer offiziellen wissenschaftlichen Terminologie kodiert ist (von ihrer nicht-dialektalen Aussprache des Phonems / t/ als gespanntem, teils aspiriertem Laut und der Überlautung des unbetonten /e/ geht die Botschaft aus: ,Ich begegne in der Vitrine fachsprachlichen Sachverhalten.').

\footnotetext{
9 Das führt vor der Vitrine „einheimische VÖGEL See“ zu einer ausführlichen Diskussion darüber, was „einheimisch“ bedeutet.
} 
Die Besucher zeigen sich also an, dass sie Hinweise im Raum auswerten, die ihnen nahelegen, Elemente ihrer räumlichen Umwelt als Zeichen zu nutzen (Exponate, Texte) und dass sie - im Einklang mit dem im Raum Signalisierten - diese Zeichen heranziehen, um in ihrer Interaktion vor der Vitrine zoologisches Fachwissen zu konstruieren. Wie die Dreiergruppe ihr Verhalten im Raum wieder an Hinweise anschließt, die stärker auf die Benutzbarkeit des Raums bezogen sind, möchte ich nicht anhand der Zaunkönigvitrine illustrieren, sondern anhand der darauf folgenden Vogelvitrine, denn erst hier stoßen die drei Besucher wieder in die Gangmitte vor.

\section{V2910, „Kibitz“}

Wie wird die Abwendung von der Vitrine hier im Detail vollzogen?

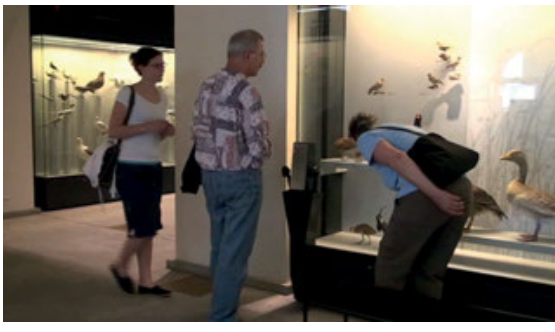

Abb. 6-3

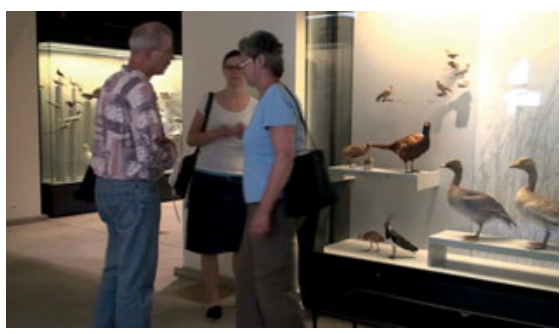

Abb. 6-5

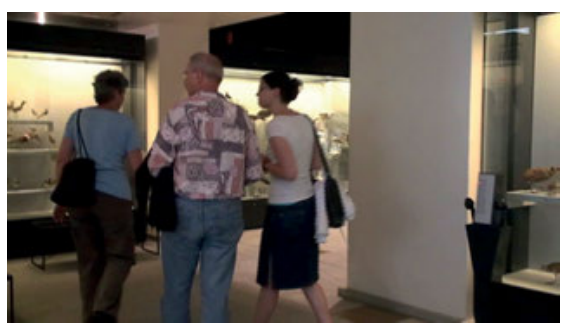

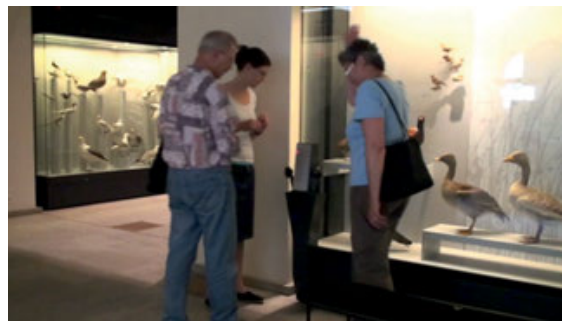

Abb. 6-4

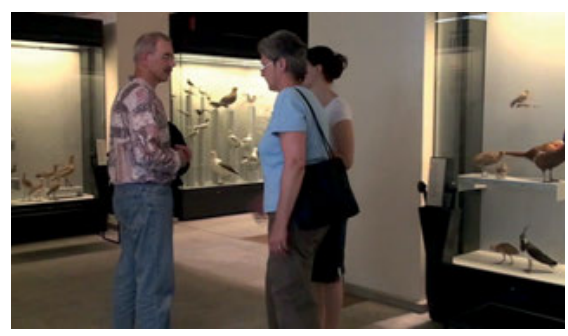

Abb. 6-6

Abb. 6-7 
- Zunächst zeigt Ännie noch ihre Beschäftigung mit einem Exponat in der Vitrine an, und zwar durch ihre stark vorgebeugte Haltung vor der Glasfront der Vitrine (Abb. 6-3), ihren zeitgleichen Kommentar „dä kibitz isch ä LUSCHtige.“ und durch die anschließende ikonische Geste, mit der sie die Haube des Kiebitzes veranschaulicht, während sie sich von der Vitrine abwendet und sich aufrichtet (Abb. 6-4).

- Doch schon mit ihrem Kommentar zum Kiebitz beginnt Ännie, sich auf Manfred zuzubewegen. Der bewegt sich in genau der gleichen Geschwindigkeit rückwärts. So entfernt er sich von der Vitrine und bleibt gleichzeitig Ännie zugewandt, mit der er im Lauf der Rückwärtsbewegung einen Blickkontakt etabliert. Zur gleichen Zeit wendet Jeanette ihren Kopf von der Vitrine ab und blickt zu ihren Eltern hin (Abb. 6-4 und 6-5).

- Manfred läuft weiter rückwärts („hasch du chei AHnig was mer alles dahei für vÖgel händ.“- Abb.6-6 gibt den Zeitpunkt wieder, zu dem Manfred die erste silbe von „VÖgel“ realisiert). Die Körper und Blicke der Besuchergruppe sind im Innern ihres o-space konzentriert, und lokaldeiktische Ausdrücke fehlen jetzt.

- Eine schnelle Umorganisation der Positionen der Gruppenmitglieder führt zu dem Zustand, der auf Abb.6-7 dokumentiert ist. Hier wird sichtbar, dass die Gruppenmitglieder die Hinweise nicht mehr nutzen (können), die von den Audiostationen oder den Exponaten in der Vitrine ausgehen: die Schrift, die die Identifikation der Exponate ermöglichen würde, ist von ihrem Weg in der Gangmitte aus nicht zu lesen, die Exponate sind nicht im Detail zu betrachten und die Audiostationen können aus dieser Entfernung weder in Gang gesetzt noch ihre Hörer genutzt werden. Auch sind die Becken und Füße der Besucher (soweit man auf sie von der Beinstellung aus schließen kann) nach vorne gerichtet bzw. auf den Gang, dessen Fortsetzung rechts im Bild zu erkennen ist.

Mit all dem zeigen sich Manfred, Ännie und Jeanette, dass sie die Hinweise, die ein Betrachten der Vitrine und ein Lesen ihrer Texte nahelegen, nun nicht mehr nutzen, selbst wenn sie sich in ihrer Nähe befinden. Gleiches leistet ihr Gespräch, das sich nun nicht mehr um konkrete Objekte im Ausstellungsraum dreht, sondern allgemein um die große Zahl unterschiedlicher Vogelarten in der Schweiz (Manfred: „ich bin jetzt (noch) überrAscht wie viu: (---) wie viu vÖgel dass mer HÄND."). Der gemeinsame Nenner all dieser Aktivitäten, die die Abwendung von der Vitrine organisieren, liegt darin begründet, dass sich die Mitglieder der Gruppe einander signalisieren, dass ihre Raumnutzung nicht mehr auf die Hinweise bezogen werden soll, die von der Vitrine ausgehen. 
Allerdings sind die Hinweise auf die ,gewünschte“ Besucherbewegung, die sich aus der Form des Gangs gewinnen lassen, an dieser Stelle des Ausstellungsraums widersprüchlich (s.o. Abb. 6-1 b): Die Wiederholung immer gleich gestalteter Vitrinen mit den ihnen zugeordneten Audiostationen kann in Verbindung mit der langgestreckten Form des resultierenden Gangs (als Vektor) als Signal verstanden werden, dass der Gang das An-den-Vitrinen-Vorbeibummeln fördert, aber ebenso, dass er für die Aneinanderreihung immer neuer Zyklen des gezielten Vitrinen-Anschauens ,gemacht ist‘ (also den Rundgang: s.o. 5.2.4).

Dass hier klare Abgrenzungshinweise zwischen Geh- und Verweilzonen fehlen, bringt es mit sich, dass hier nur äußerst geringe Bewegungs- oder Richtungsänderungen notwendig sind, um bald die einen Hinweise (Weitergehen!), bald die anderen (Betrachten! Lernen!) nutzen zu können, wie die folgenden Standbilder dokumentieren:

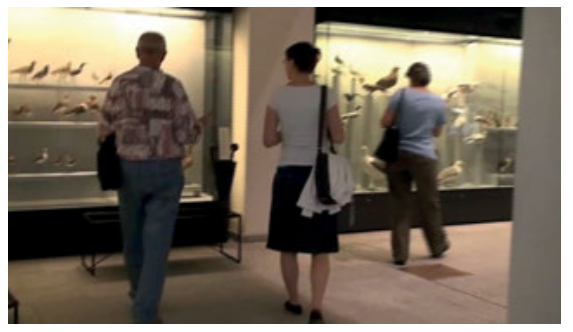

Abb. 6-8

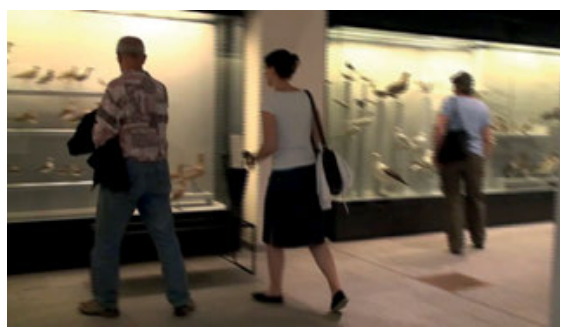

Abb. 6-10

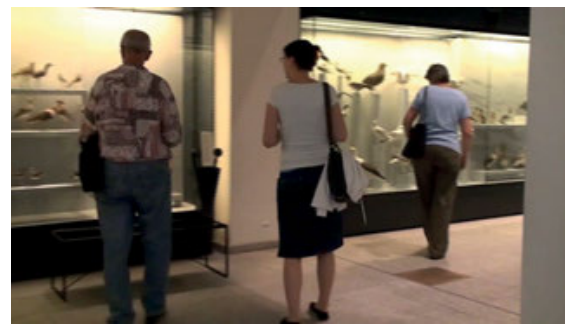

Abb. 6-9

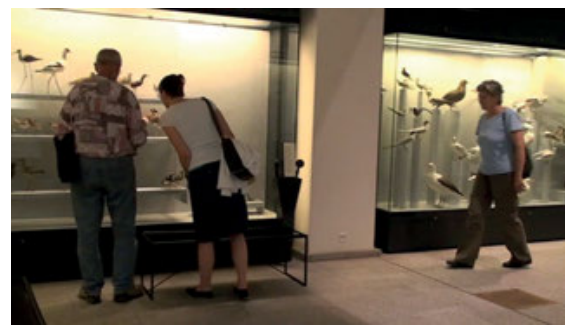

Abb. 6-11

Hier reicht ein kleiner, plötzlicher Schwenk Manfreds aus - in Sekundenbruchteilen übernommen von Jeanette, die neben ihm hergeht -, um das suchende Bummeln wieder in eine stationäre Phase der intensiven Beschäftigung mit einer Vitrine übergehen zu lassen.

- Abb. 6-8 zeigt den vorletzten Schritt von Manfred und Jeanette, der noch als Schritt im Vitrinengang verstehbar ist, in Abb. 6-9 sieht man, wie Jeanette 
ihren rechten Fuß leicht nach links eindreht. Das reicht offensichtlich als Signal, dass sowohl Jeanette als auch Manfred ihre Gehrichtung plötzlich ändern (Abb. 6-10). Die plötzliche Richtungsänderung legt nahe: Sie steuern links auf eine Vitrine zu, die „Einheimische VÖGEL See“ überschrieben ist.

- Zwei Schritte näher an die Vitrine heran, und Manfred und Jeanette stehen links bzw. direkt hinter dem Bänkchen, das (wie oben beschrieben) ein Weitergehen behindert (Abb.6-11), und Jeanette demonstriert mit einem Vorbeugen, dass ihre Aufmerksamkeit in der Vitrine konzentriert ist. Gleichzeitig sind nun die Exponate und ihre Beschriftung so gut $\mathrm{zu}$ erkennen, dass Manfred mit der Identifikation eines der Exponate beginnen kann („KAMPFläufer.“).

Zusammenfassend: Im Vogelvitrinen-Gang gibt es Hinweise darauf, dass er zum An-den-Vitrinen-vorbei-Bummeln wie zum Vitrinen-Betrachten einlädt. Welche Hinweise sie jeweils gerade nutzen, zeigen sie sich durch ihr sprachliches wie nicht-sprachliches Verhalten jederzeit an: Können ihre Positionierung im Raum oder ihre Beiträge auf die Hinweise bezogen werden, die sich aus der Vitrine gewinnen lassen (und die weiter oben beschrieben worden sind), können wir ihr Verhalten im Raum als Beschäftigung mit der Vitrine verstehen, gestalten sie ihre Position im Raum dagegen so, dass sie die Hinweise der Vitrine nicht nutzen können, dann sehen wir sie als Menschen, die durch den Gang bummeln (in Ausnutzung der Bewegungshinweise, die die langgestreckte Form des Gangs gibt). Die große Nähe von Geh- und Verweilzonen macht, dass die Besucher durch minimale Bewegungen ihre Orientierung bald an den einen, bald an den anderen Hinweisen sichtbar machen können, wodurch sie beinahe nahtlos von einem schnellen An-den-Vitrinen-Vorbeibummeln zur gezielten Beschäftigung mit einer bestimmten Vitrine übergehen können (und umgekehrt).

Einige Präzisierungen zum Status der Hinweise und zu der Frage, wie die Hinweise aus der Interaktion der Besucher $\mathrm{zu}$ rekonstruieren sind, erscheinen mir noch notwendig zu sein. In meinem Videokorpus lässt sich häufig belegen, dass sich die Besucher in ihrem Verhalten am Gesamt der Hinweise in ihrer räumlichen Umgebung orientieren, während es nicht gelingt, die Orientierung an einzelnen Hinweisen schlüssig nachzuweisen. Hierfür ist das obige Beispiel „Zaunkönig“ ein gutes Beispiel. Dort lässt sich meines Erachtens plausibel machen, dass die drei Besucher die Vitrine als Gliederungselement im Raum interpretieren, das gleichsam eine ,natürliche Portionierung، der Rezeption anbietet, indem man darauf verweist, dass die drei Besucher hier lange stationär vor der einen Vitrine verharren, dann rasch zur benachbarten Vitrine vorrücken, vor der sie wieder lange verweilen. Die zeitliche Gliederung ihrer Interaktion, in deren sukzessives Fortschreiten sie Zäsuren einbauen, deren Anfangs- und Endpunkte sie interaktiv 
aushandeln, kann verstanden werden als beobachtbar anknüpfend an die durch die Vitrine signalisierte Gliederung des dauerkommunikativen Angebots im Raum, als deren Aktivierung für die Dynamik der Interaktion. Auf welche Hinweise im Einzelnen ihre Interpretation der Vitrine als Gliederungseinheit zurückgeht, wird in diesem kurzen Ausschnitt weder sichtbar gemacht noch verbalisiert: Basiert sie auf dem Glaskasten, der alle Exponate umgibt? der Vitrinennummer am oberen Metallrahmen? auf der Änderung der Ausrichtung der Vitrinenfront, die die erste von der zweiten Vitrine trennt? auf dem Musterwissen, dass die Form ,der Vitrine wiedererkennt und mit ihrer Gliederungsleistung im Rahmen von Ausstellungen vertraut ist? Gerade die Nutzungen des Raums, die auf der Vertrautheit mit der Musterhaftigkeit der Ausstellung basieren, dürften sich in aller Regel aus der ganzheitlichen Auswertung eines breiten Spektrums von als musterhaft (wieder) erkannten Hinweisen speisen.

Und doch gibt es Fälle, in denen die Interpretation genau eines Hinweises an die ,Oberfläche‘ der Interaktion tritt. Einige wenige Beispiele aus meinem Korpus sollen illustrieren, dass diese Fälle nicht auf eine spezifische Art von Hinweisen beschränkt sind:

- Abgrenzungshinweis: Großmutter „Mona“ (MO) signalisiert ihrem Enkel „Tommy“ (V0300), dass die Glasscheibe der Vitrine als Abgrenzungshinweis $\mathrm{zu}$ verstehen ist (und zwar im Hinblick auf die gestatteten Bewegungen der Besucher). Konkret: Sie hält ihre flache Hand vor die Vitrinenscheibe und verhindert so, dass Tommy die Vitrine berührt. Zur Begründung des Berührungsverbots verweist sie auf die Zerbrechlichkeit des Glases und die Transparenz, die durch „Tapsen“ herabgesetzt wird:

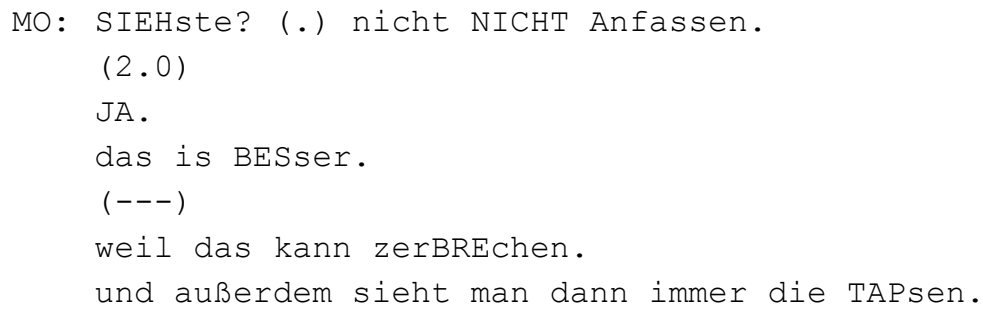

- Verknüpfungshinweise: Großmutter „Veronika“ (VR) macht im Video V2780 ihr begleitendes Enkelkind darauf aufmerksam, dass es ein kleines Lämpchen am Fuß des Vogelexponats als Verknüpfungshinweis auswerten soll: Das Lämpchen markiert immer den Vogel, dessen Stimme gerade an der Audiostation abgespielt wird. Der Verknüpfungshinweis wird hier in Form einer allgemeinen Regel formuliert: „,immer wo s LÄMPli lüüchtet DÄ isch es.“: 
VR: LUEg emal.

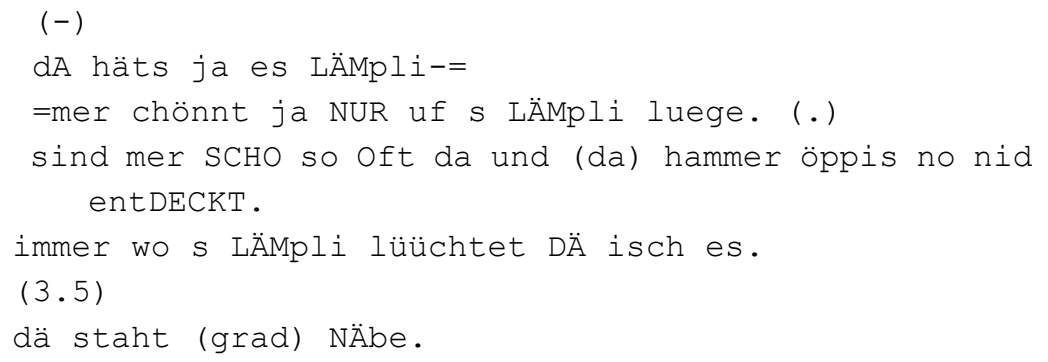

- Themahinweis: Besucherin „Therese“ (TH) signalisiert ihrer Begleiterin „Heike“ (HE) im Video V4300, welche Eigenschaften zweier Exponate sie als Beitrag zur Konstruktion eines gemeinsamen Themas versteht, nämlich den Kontrast von ursprünglichem Aussehen und dem Aussehen nach der Aufbereitung durch die Ausstellungsverantwortlichen:

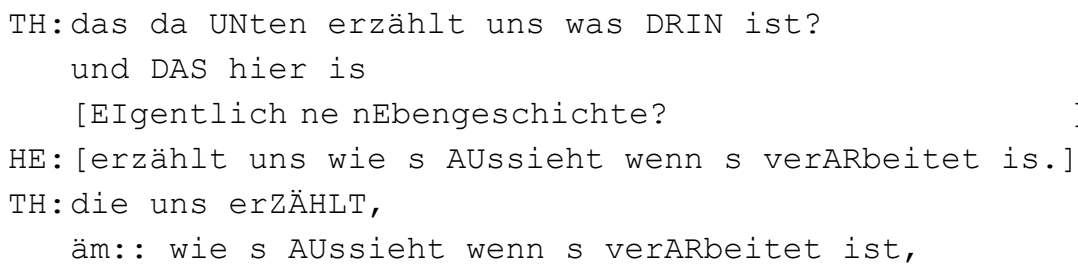

In all diesen Beispielen geben die Besucher Rechenschaft über ihre Nutzung einzelner Hinweise im Raum.

\subsection{Hinweis-Analyse: Problematische Fälle}

Bis hierher habe ich dafür argumentiert, dass man die Nutzung des Raums durch die Interaktionsbeteiligten als Online-Auswertung von sinnlich wahrnehmbaren Hinweisen in der räumlichen Umwelt verstehen kann, die erst mit ihrer Beanspruchung durch die Interaktionspartner als Hinweise emergieren. Wird aber mit dem Hinweis-Konzept nicht gleichsam ,durch die Hintertür ${ }^{`}$ die Idee einer Determinierung der Interaktion durch die als gegeben gedachten Eigenschaften des Raums wieder eingeführt? Wenn das Hinweis-Konzept keine solche Umformulierung der Raumdeterminierung sein soll, dann müssten sich Fälle finden lassen, in denen die Museumsbesucher den Raum nicht so nutzen, wie von den Hinweisen suggeriert. 
Ströker (2011: 227) beschreibt aus phänomenologischer Perspektive ein Raumverhalten, dass das vom Raum Nahegelegte „negiert“:

Ich kann [den Raum] durch meine Bewegung negieren, kann mit ihr dokumentieren, daß ich mich seinem Gehalt verschließe - wodurch der Raum nicht bleibt was er eben war, sondern augenblicklich verwandelt wird [...].

Genau so eine Raumnutzung, mit der die Teilnehmer von dem abweichen, was sie aus den Hinweisen im Raum als erwartbare Nutzung erschließen (mit der Folge, dass der Raum eine neue Bedeutung erhält), muss im Rahmen des Hinweis-Konzepts möglich sein.

Das wirft die Frage auf, woran wir in den Videodaten erkennen können, ob das Raumverhalten der Besucher ihrer Auswertung der Hinweise im Ausstellungsraum entspricht oder ob sie sich im Gegenteil anders verhalten, als es ihre Auswertung der Hinweise im Raum nahelegen würde. Die Antwort ist erneut im konversationsanalytischen Prinzip des display zu finden: Wenn die Interaktionsbeteiligten den Raum anders nutzen, als es die von ihnen ausgewerteten Hinweise im Raum erwartbar gemacht haben, dann steht zu erwarten, dass sie sich diese Tatsache gegenseitig signalisieren. Eine solche abweichende Nutzung könnte sich in den Daten darin zeigen, dass die Abweichung im Gespräch durch einen account thematisiert wird, sie könnte Gegenstand von Reparaturen werden, sei es durch den ,subversiven' Raumnutzer selbst, sei es durch andere Anwesende, sie könnte durch körperliche Ausdrucksmittel angezeigt werden (im Sinne eines „body gloss“, Goffman 1971: 122) usw. Umgekehrt sollte sich eine den Hinweisen im Raum folgende Nutzung des Ausstellungsraums darin zeigen, dass die Interaktionsteilnehmer den Raum in einer unauffälligen, ökonomischen Weise nutzen, die die Raumbezogenheit ihrer Interaktion vollständig unter der Aufmerksamkeitsschwelle bleiben lässt. Im Folgenden möchte ich eine Reihe von Beispielen anführen, in denen das Verhalten im Raum für manche Besucher offensichtlich problematisch wird.

Im ersten Beispiel („Labyrinth“) geht es um die Auswertung von problematischen Bewegungshinweisen im Raum, die dazu führt, dass ein Besucherpaar sich für eine Zeitlang getrennt durch den Raum bewegt, bevor sie ihren Gang durch das Museum wieder gemeinsam fortsetzen. Die Auswertung der Hinweise, die die erwartbare und erlaubte Bewegung durch den Raum betreffen, wird dabei hörbar und - in Form eines „body gloss“ sichtbar. Das zweite Beispiel („Giraffe“) dokumentiert eine subversive Raumnutzung durch ein Kleinkind: Es nutzt eine Vitrine und ein freistehendes Giraffenpräparat als Trainings- und Spielgeräte. Bei der Analyse dieses Beispiels geht es mir darum, wie die Frage, ob eine Nutzung den Benutzbarkeitshinweisen im Raum entspricht oder nicht, durch Mutter und Kind 
gemeinsam ausgehandelt wird. Das letzte Beispiel („Bummelstudenten“) zeigt eine Gruppe von Studierenden, die sich gegenseitig anzeigen, dass die Hinweise im Ausstellungsraum, die für deren Nutzung im Sinne der Kommunikation in der Ausstellung sprechen, für ihre Interaktion gerade keine Relevanz besitzen.

Das folgende Transkript dokumentiert einen Ausschnitt aus dem Rundgang zweier Besucher durch die Sonderausstellung „Galápagos“ im Zoologischen Museum. Abb.6-12 illustriert die räumliche Situation, die sich den Besuchern präsentiert.

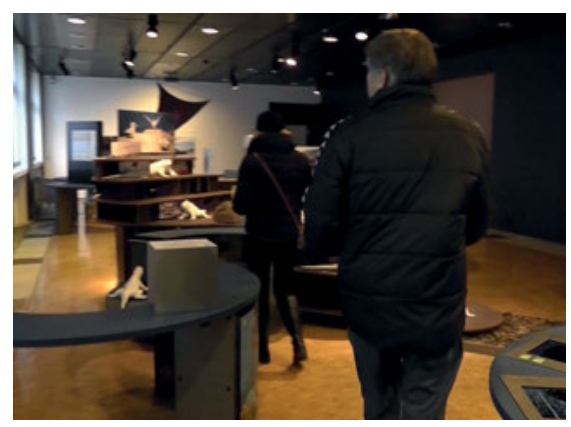

Abb. 6-12

\section{V3853, „Labyrinth“}

01 SY: \#aHA:, (-)

$\# 1$

02 SCHÖ:N, (--)

03 (s hät) BILDli; gäll, (--)

04 aiaiAi;

05 RO: so_öppis söllt mer [ma natU i de naTUR usse gseh.]

06 SY: [WART emal wo gahts denn hier
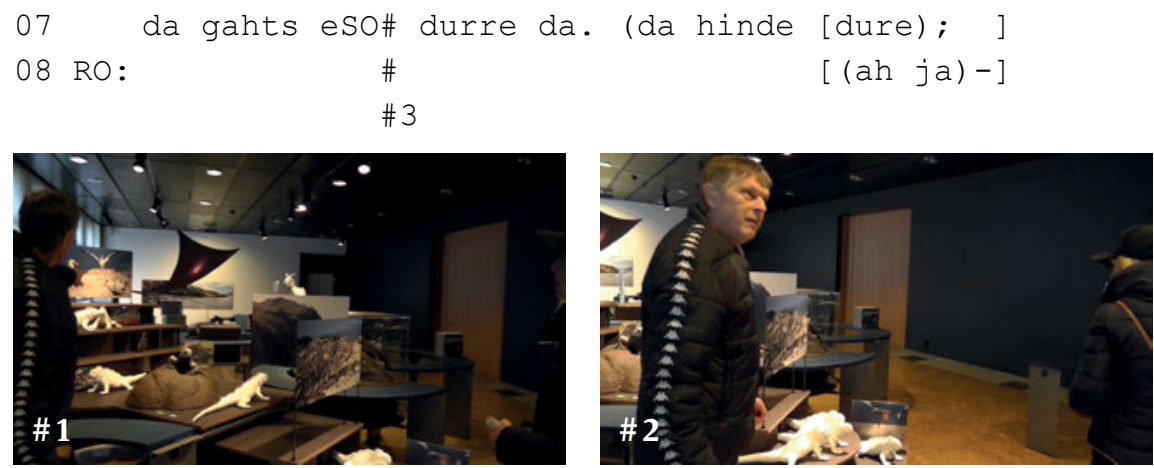

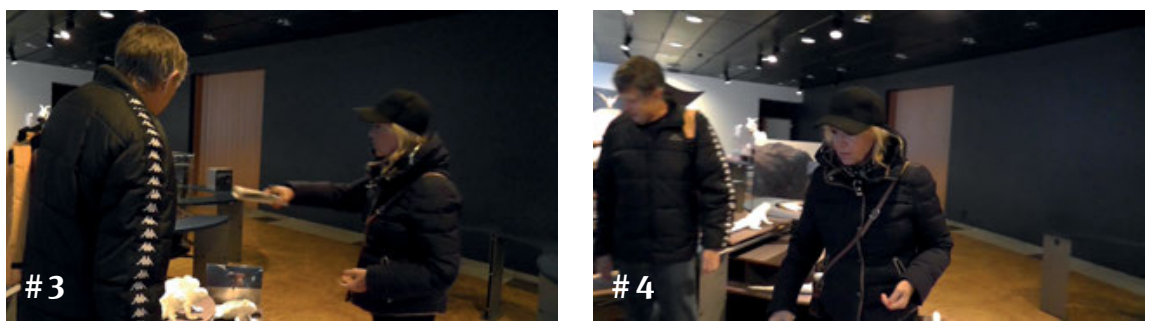

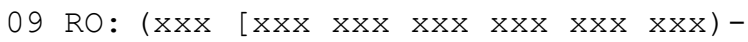

10 SY: [wart eso:?

11 \#JA? (.)

\#4

12 DA: ?\# (-)

\# 5

13 RO: nEI dett hinde NÖD; \#

\# 6
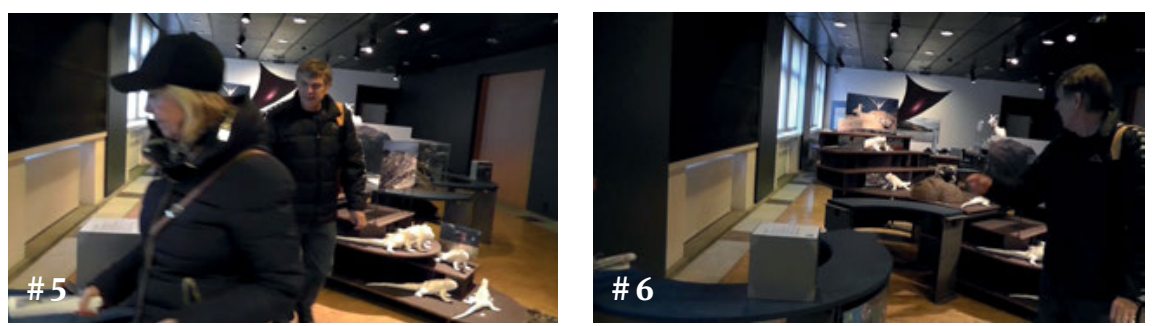

14 SY: wo? \#WEISCH dett hIndere;

\# 7

15 RO: ah_JA-

16 SY: dett cha? \#dEtt häts $<<$ lachend>ja \#SCHTEI,\#
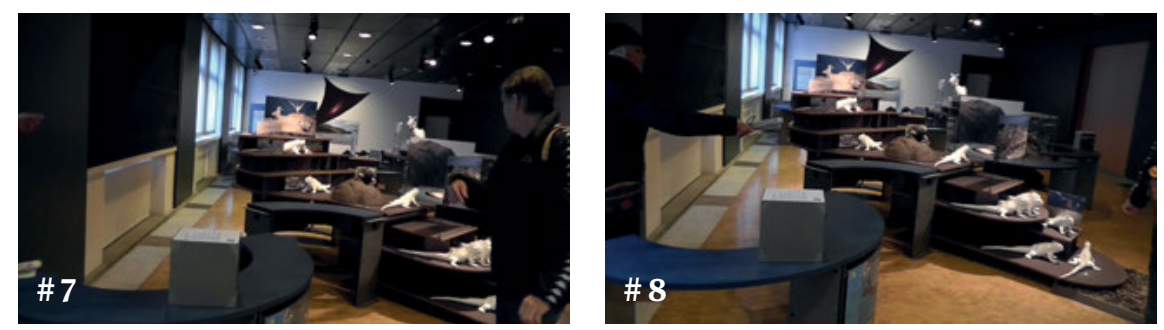

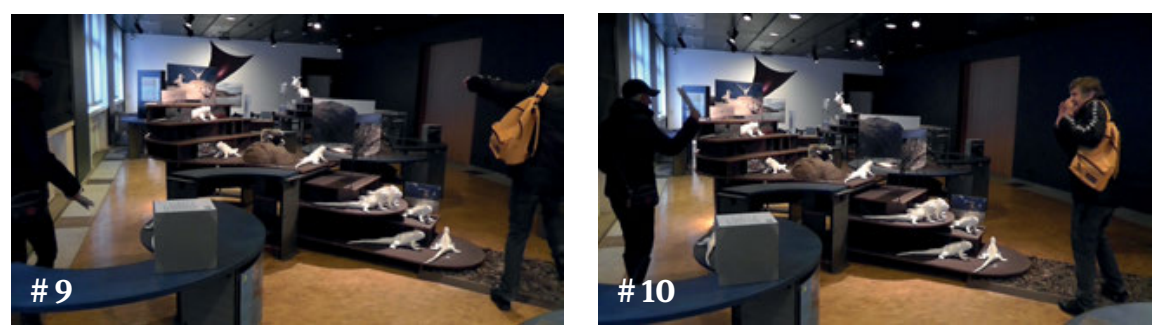
17
was ((lacht)) ${ }^{\circ} \mathrm{h}$ was \# (XXX), $\# 11$
18
$(\mathrm{XXX} \times \mathrm{xx}$ ja), $>\#(-) \#$
\#12 \#13
19 RO: naNEI das GAHT\# scho da, $\# 14$
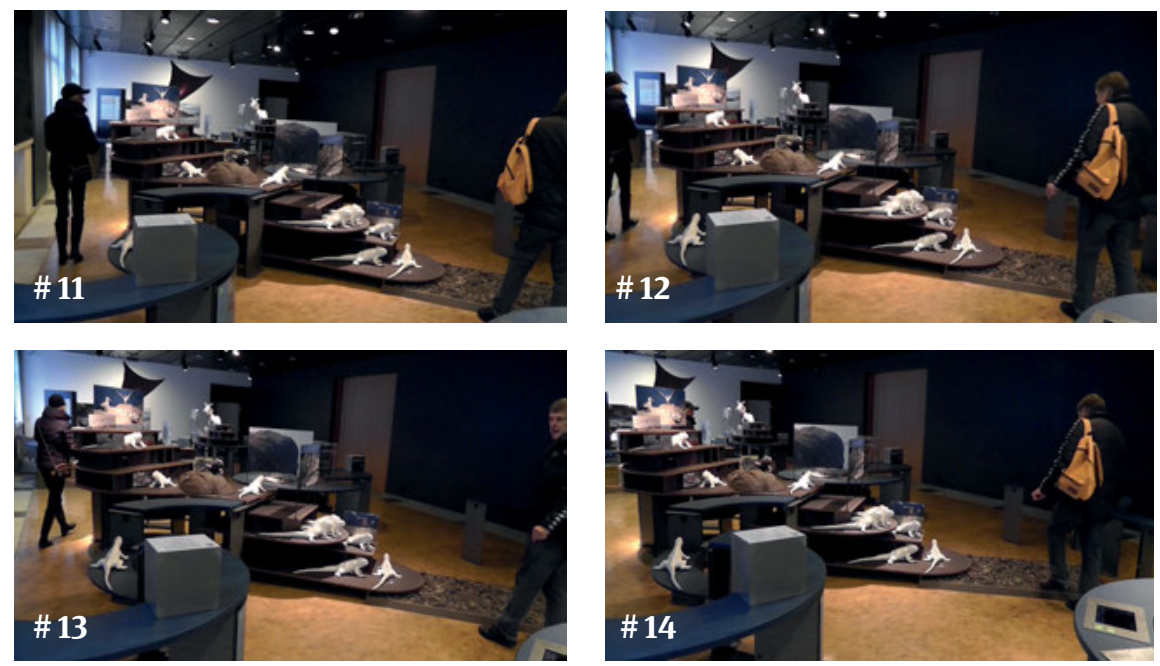

20 SY: !UI!;

21 (des),

22 (JA), \#

\# 15

23 RO: (xxx xxx $x x x) \#$ 

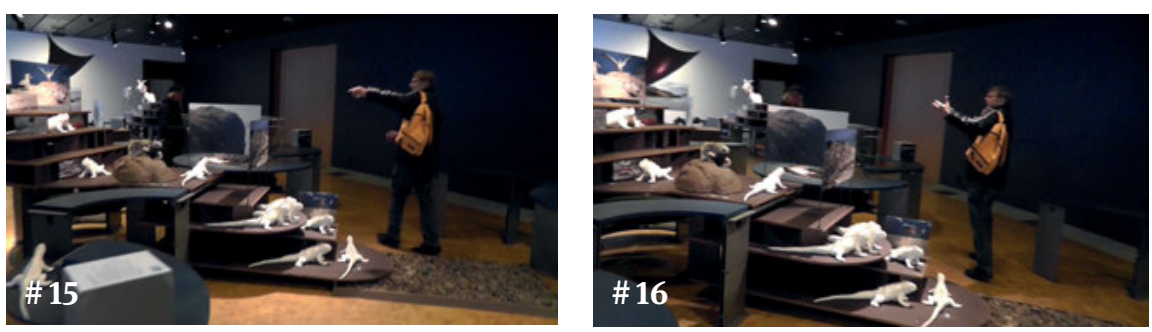

24 SY: es la?\# (.) es isch wIE_n_es labyRINTH;

$\# 17$

$25 \mathrm{RO}:<<\mathrm{p}>\mathrm{JA},>$

26 SY: \#wa_sch jetzt DAS für en Vogel hier, \#18
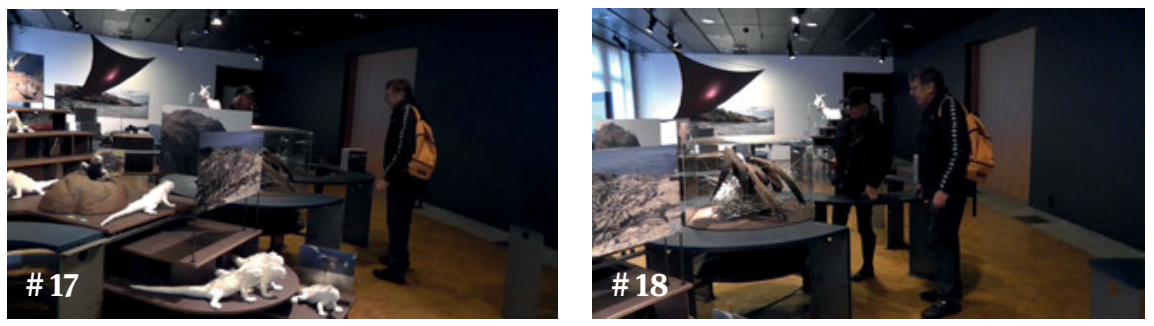

Hier wird die Bewegung durch die Ausstellung zum praktischen Problem.

- Zu Beginn des hier präsentierten Ausschnitts betrachten die beiden Besucher „Roman“ (RO) und „Sybille“(SY) eine Installation mit Leguanen und einigen großformatigen Fotos (\#1). Dann wenden sie sich von der Installation ab und beginnen, sich nach rechts zu bewegen (\#2). Doch offenbar sieht Sybille keine Hinweise, die nahelegen, dass dies ein legitimer Weg zu den noch nicht betrachteten Exponaten wäre: „wo gahts denn hier DUre?“ (Z. 6). Das Objekt, das für Sybille im Hinblick auf die Bewegungsmöglichkeiten problematisch ist, ist eine Art ,Beet‘ aus Lavasteinen, die sich an die Leguan-Installation anschließt (sichtbar auf Abb. 6-12). Das Lavastein-,Beet' stellt kein wirkliches physisches Hindernis für den Weg durch den Raum dar, es wäre mit zwei Schritten zu überqueren. Und doch kehrt Sybille um und wählt einen alternativen Weg: einen schmalen Durchlass zwischen einem Geländer und der Wand, der sie um die Rückseite der Leguan-Installation herumführt („hinde DUre“, Z. 7).

- Während Sybille der Weg über die Lavasteine offenbar als versperrt erscheint, erklärt sie den Durchlass zu einem legitimen Weg durch die Ausstellung (,da 
gahts“, Z. 7) und versucht, Roman ebenfalls zur Benutzung des Durchgangs zu bewegen, indem sie vorgeht und mit den zusammengerollten Papieren, die sie in der Hand hält, den weiteren Weg vorzeichnet (\#3). Roman folgt ihr zunächst (\#4), bleibt dann stehen und entscheidet sich offensichtlich gegen ihren Vorschlag („,nEI dett hinte NÖD;“, Z. 13, \#5 bis \#7): Er geht auf das Lava-,Beet‘ zu (\#8).

- Sybille macht sich über Romans Alternative lustig: „dEtt häts <<lachend>ja \#SCHTEI, “ (Z. 16, geäußert in einem Tonfall, der den von ihm eingeschlagenen Weg als völlig abwegig erscheinen lässt, Zeigegeste auf das ,Beet‘: \#8). Roman aber steigt mit einem Bein in das ,Beet‘ und gerät aus dem Gleichgewicht (\#9). Das kommentiert er, indem er Sybille anschaut und die Hände vor den Mund schlägt (\#10), interpretierbar als: ,Was habe ich da (lustigerweise) Verbotenes getan!' Das Betreten der Steine wird also durch Romans „body gloss" als eine Raumnutzung entgegen der Hinweise markiert, die legitime Bewegungsmöglichkeiten im Ausstellungsraum kennzeichnen. Allerdings handelt es sich bei Romans abweichender Nutzung des Raums nicht um einen Verstoß, der wirklich schlimm ist, denn offenbar sind hier keine weiteren Entschuldigungen oder Rechtfertigungen notwendig. Die abweichende Raumnutzung lässt sich einfach ,weglächeln'.

- Dennoch bleibt der Weg über die Steine für Roman problematisch. Obwohl Sybille seinem ,transgressiven' Raumverhalten gleichsam Absolution erteilt hat, indem sie seinen ,Kletterversuch' nach einer wegwerfenden Geste (\#10) nicht weiter beachtet (\#11), demonstriert Roman aufwändig im Raum seine Suche nach Alternativen, indem er seinen Kopf hin- und herdreht (\#11 bis \#13). Nach dieser Suche nach Alternativen bewertet er den Weg über die Lavasteine als einen nun doch möglichen: „naNEI das GAHT scho da,“ (Z. 19). Und erst mit dieser Neubewertung steigt er über die Steine (\#14). Dieses Mal kennzeichnet er diese Bewegung nicht mehr als abweichend. Aber mit Zeigegesten, die aussehen, als fahre er mit ihnen eine Reihe verwirrender Bewegungsalternativen ab (\#15), und einer anschließenden konventionellen Geste der Ratlosigkeit (\#16) verdeutlicht er, dass er keine Hinweise für andere Bewegungsmöglichkeiten gefunden hat, dass also der Weg über die Steine für ihn gleichsam die ,letzte Möglichkeit‘ gewesen ist, zu den noch nicht betrachteten Exponaten zu gelangen.

An diesem Beispiel konnten wir sehen, wie Besucher es sich aufzeigen können, dass sich ihre Nutzung des Raums nicht in Einklang mit von ihnen ausgewerteten Nutzungshinweisen befindet, hier konkret: mit Hinweisen auf die Organisation der Bewegung durch den Ausstellungsraum (s.o. 3.3). Wir sehen auf dem Video zwar, dass Roman das Lavastein-,Beet‘ übersteigt. Aber mit seinem Übersteigen 
verdeutlicht er seiner Begleiterin Sybille (ebenso wie möglichen Beobachtern), dass dieses Übersteigen für ihn problematisch ist.

Wenn Sybille den Ausstellungsraum abschließend als „wIE_n_es labyRINTH; “ bezeichnet (Z. 24), dann bringt sie damit noch einmal ihre Schwierigkeiten, die Bewegung durch den Raum zu organisieren, auf den Begriff. Interessant ist dabei, dass sich diese Schwierigkeiten nicht aus irgendwelchen handfesten Bewegungshindernissen ergeben. Außer der flachen Einfassung, die verhindert, dass sich die losen Steine durch den Ausstellungsraum verteilen, gibt es nichts, was einem Betreten des Lava-,Beets، physisch im Wege stünde. Der Weg über die Steine ist vielmehr deswegen problematisch, weil es Hinweise gibt, die suggerieren dass das ,Beet“ Bestandteil der Leguan-Installation (also eines Exponats) ist: unregelmäßige, lockere Steine als ungewöhnliche, ja sogar gefährliche Materialien für einen Bodenbelag, eine schmale Umrandung, die dem ,Beet‘ den Charakter eines niedrigen Podests gibt, die Nähe zu beschrifteten und beleuchteten Tierpräparaten usw. Gleichzeitig lassen sich aber Hinweise dafür finden, dass das ,Beet‘ ein Durchgehen ermöglichen soll: die Unterbrechung des ansonsten durchgehenden Handlaufs sowie die Breite dieser Unterbrechung, die (im Gegensatz zu dem schmalen Durchgang, den Sybille nutzt) ein Nebeneinanderhergehen ermöglicht. Das Bewegungsproblem tritt also genau dort auf, wo eine semiotischtextlinguistische Analyse der Kommunikation durch die Ausstellung das Vorliegen von undeutlichen und widersprüchlichen Hinweisen rekonstruieren würde.

Im nächsten Ausschnitt („Giraffe“) nutzt ein etwa einjähriges Kind („Marcos“, MC) den Ausstellungsraum als Spielplatz. Hieran möchte ich illustrieren, wie Besucher den Grad der ,Subversion', der mit einer alternativen Raumnutzung verbunden ist, gemeinsam aushandeln können. Da hier der Anteil des Nonverbalen den des Verbalen bei Weitem überwiegt, organisiere ich das folgende Transkript entlang der Standbilder, und nicht entlang der Tonspur.

\section{V8742, „Giraffe“}
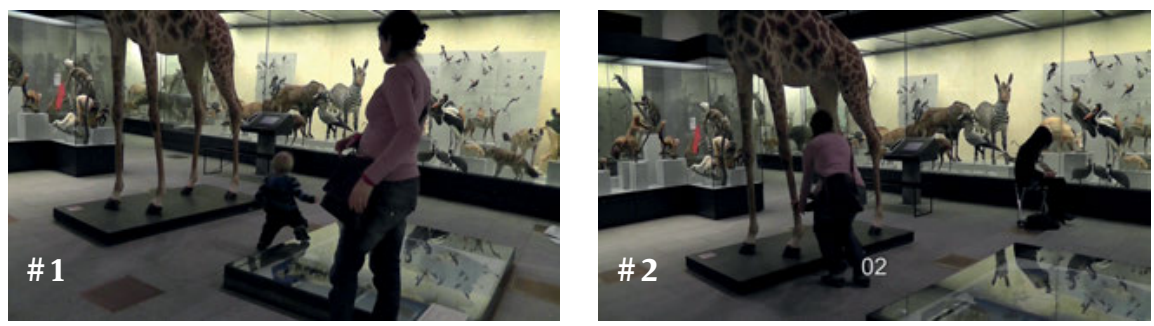

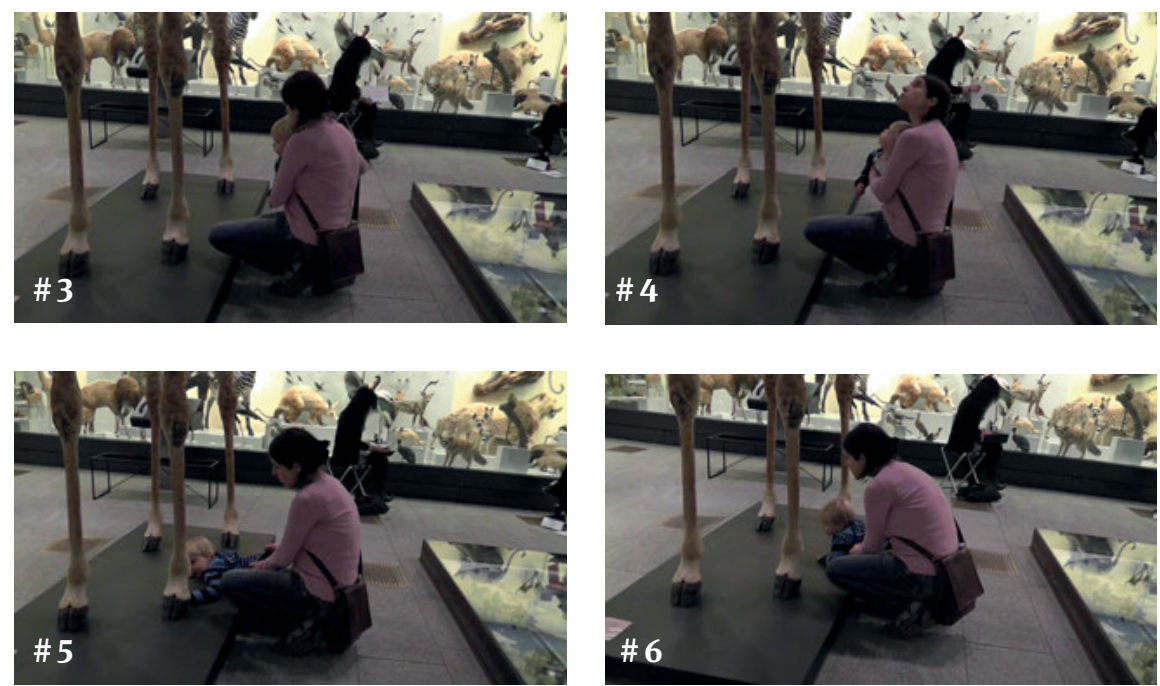

\#(1.6) MARcos, mer tüend s NED \#Alange;
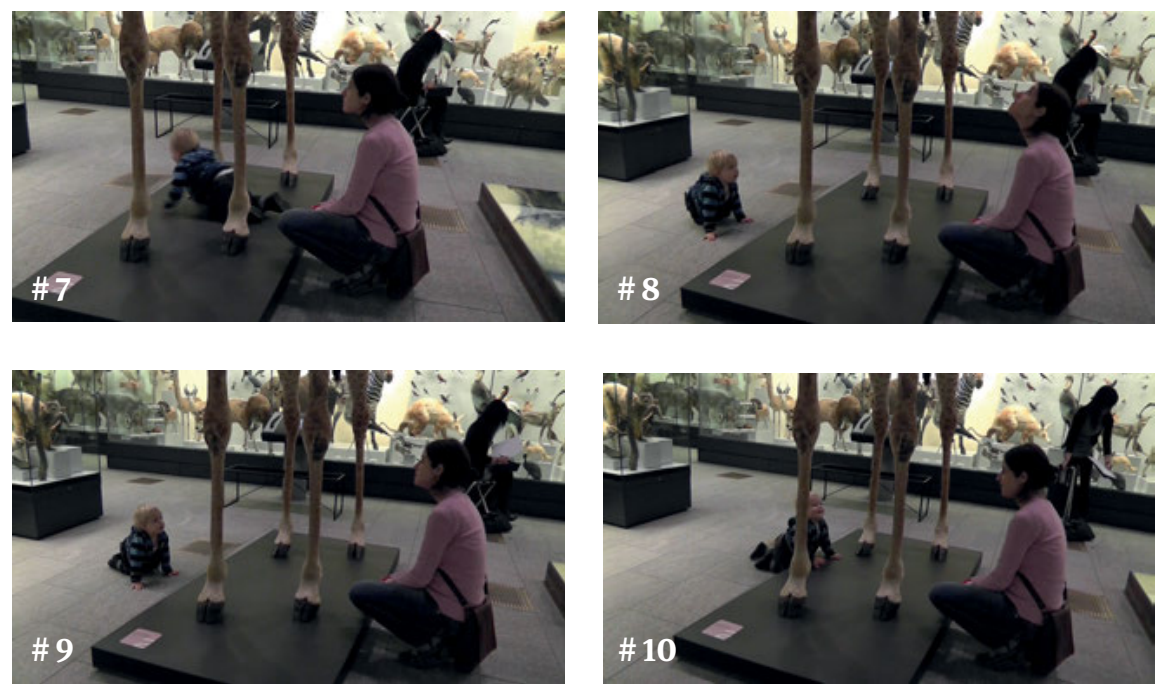

\# ((Klopfen)) (1.2) MARcos

no te pAses. 


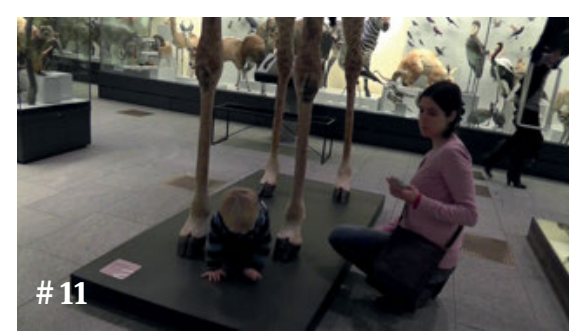

Wie wird also in dem Ausschnitt „Giraffe“ das Verhalten des Kindes Marcos als ,subversive‘ Nutzung des Raums konstruiert, als eine Nutzung, die den Raum und seine Hinweise gleichsam ,gegen den Stricht liest‘?

- Gleich Beginn macht Mutter Bea deutlich, dass Marcos‘ Umgang mit dem Exponat nicht angemessen ist: Als Marcos auf das Giraffenexponat zugeht (\#1) und es an einem der Beine umfasst, springt Be schnell herbei und zieht seinen Arm zurück (\#2). Auf seine Gegenwehr hin zieht sie ihn vom Podest herab und stellt ihn neben sich auf den Boden (\#3).

- Einen kurzen Moment betrachten sie zu zweit die Giraffe (\#4), nutzen sie also im Rahmen der Ausstellungskommunikation als Exponat. Dann aber reißt sich der Junge los, lässt sich auf das flache Podest fallen, auf dem die Giraffe steht, und streckt sich nach dem Giraffenbein (\#5). Die Mutter kommentiert „MARcos, (mer tüend s) NED Alange;“ und zieht ihn zurück (\#6). Zum zweiten Mal signalisiert die Mutter ihrem Kind, dass die Berührung des Giraffenexponats unangemessen ist (hier durch eine Regel, die auch für die Mutter gilt: „mer“) und unterbindet die Berührung physisch.

- Als Bea die Hände wegnimmt, nutzt Marcos das aus, um flink zwischen den Beinen der Giraffe durchzukrabbeln (\#7). Auf der anderen Seite angekommen, dreht er sich um und schaut seine Mutter Bea herausfordernd an, wie um sie in ein Spiel zu verwickeln (\#8). Diese hat - wie es scheint: demonstrativ - die von den Hinweisen im Ausstellungsraum ,geforderte، Betrachtung des Exponats wieder aufgenommen, doch Marcos folgt diesem Verhalten nicht. Daraufhin nimmt sie Blickkontakt mit dem Jungen auf (\#9), und beide schauen sich längere Zeit starr an, wie in einem stummen Kräftemessen. Schließlich krabbelt Marcos seiner Mutter grinsend entgegen und schlägt mit der Hand laut auf das Podest (\#10), woraufhin sie ihn ermahnt „MARcos no te pAses.“ (,Marcos, überspann den Bogen nicht!‘). Mit anderen Worten: Sie bezeichnet das Verhalten ihres Sohnes als Herausforderung an sie, als ein Verhalten, das droht, die Grenze des Angemessenen zu überschreiten (span. pasarse de la raya wörtl. ,über den Strich hinausgehen').

- Schließlich nutzt Marcos die Tatsache, dass sich seine Mutter ihrem Telefon zuwendet und schlüpft durch zwei Beine der Giraffe (\#11). Dass er das Spiel 
mit der Giraffe genau in dem Moment wieder aufnimmt, als Bea ihre Aufmerksamkeit von ihm abwendet, verleiht Marcos‘ Aktion den Charakter des Verbotenen.

Hier ist es nun nicht so, dass das Kind die Benutzungshinweise, die sich aus dem im Raum Wahrnehmbaren gewinnen lassen, vollständig ignorierte (das Podest, das darauf hinweist, dass wir es nicht mit einem normalen Objekt, sondern eben mit einem Ausstellungsstück zu tun haben, die Objektkennung, die nahelegt, dass es über das Exponat etwas zu erfahren und zu lernen gibt, die Tatsache, dass es sich bei der Giraffe um ein Tier handelt, wodurch sich die Giraffe zwanglos in den thematischen Zusammenhang des Museums einfügen lässt usw.). Vielmehr nutzt er für sein Tun andere Hinweise im Raum. Das flache Podest, auf dem die Giraffe steht, ist ja so hoch, dass es die Möglichkeit eines Daraufkletterns signalisiert, das Fehlen einer schützenden Glashülle lässt ja die Möglichkeit eines Berührens erkennen, und Abstand und Länge der Giraffenbeine können als Hinweis darauf gelesen werden, dass hier eine Person durchkrabbeln oder gebückt durchgehen kann. Mit anderen Worten: Auch das transgressive Verhalten im Raum schließt an Hinweise im Raum an (wenn sich die Interaktionspartner nicht die Unabhängigkeit ihrer Interaktion von dem sie umgebenden Raum signalisieren, wie im letzten Beispiel, dem Ausschnitt „Bummelstudenten“, s.u.). Dass Marcos“ Verhalten hier als transgressive Raumnutzung erscheint, als Raumnutzung, die die Hinweise im Raum gleichsam ,gegen den Strich liest', ist das Ergebnis einer gemeinsamen Aushandlung in der Interaktion. Sowohl der Junge als auch seine Mutter machen Marcos' Verhalten zur transgressiven Nutzung: der Junge durch seinen Versuch, den Blick der Mutter auf sich zu lenken, seinen herausfordernden Blick, das Fortsetzen der inkriminierten Aktivitäten nach der Ermahnung der Mutter usw.; die Mutter durch die ,handgreifliche‘ Korrektur seiner Bewegungen im Raum, die explizite Formulierung von Verhaltensnormen und die Bezeichnung seines Verhaltens als ein Über-die-Stränge-Schlagen (pasarse). Durch die Aushandlung dessen, was als transgressive Raumnutzung gelten soll, legen die Besucher indirekt auch fest, welche Hinweise im Raum als die dominanten, die für die Bestimmung der legitimen Nutzungsmöglichkeiten des Raums relevanten, herangezogen werden sollen.

In Szenen wie der hier dargestellten geht es also auch darum, Kindern zu vermitteln, wie die Hinweise im Raum richtig auszuwerten sind (und wie die Hinweise richtig zu hierarchisieren sind). Hierzu gehört auch, dass Marcos die Verbindung zwischen der Nutzung der angemessenen Hinweise und der Teilnahme am gemeinsamen Museumsbesuch erfährt: Seine Nutzung der unangemessenen Hinweise zieht direkt im Anschluss an den hier wiedergegebenen Ausschnitt „Giraffe“ den Abbruch des gemeinsamen Museumsbesuchs nach sich. 
In den vorausgegangenen Beispielen war der Ausstellungsraum auch dann als die räumliche Umwelt der beobachteten Interaktion wichtig, wenn der Raum nicht im Sinne der Ausstellungskommunikation genutzt wurde. Das abschließende Beispiel soll nun den Fall illustrieren, dass die Relevanz der Hinweise im Ausstellungsraum in einem Interaktionsereignis derart herabgestuft werden kann, dass der Eindruck entsteht, das betreffende Interaktionsereignis finde völlig losgelöst von seiner räumlichen Umwelt statt. Bei dem Beispiel „Bummelstudenten“ handelt es sich um die letzten Minuten des gemeinsamen Museumsbesuchs einer Gruppe von drei Studenten. Diese schlendern dem Ausgang zu und unterhalten sich angeregt miteinander, inspiriert durch die zuvor betrachteten Exponate von Riesenhirsch und Mammut.

\section{V1024, „Bummelstudenten“}
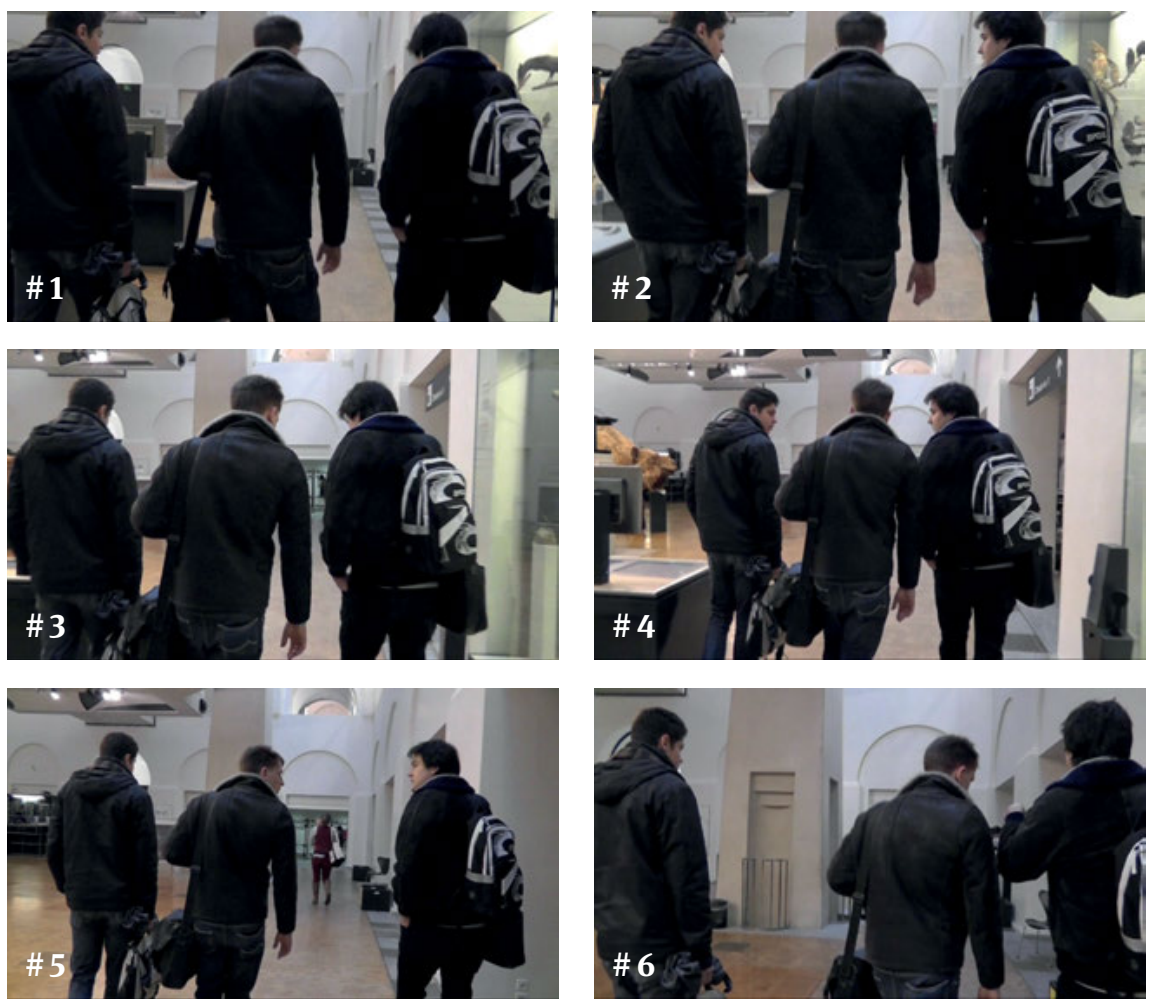

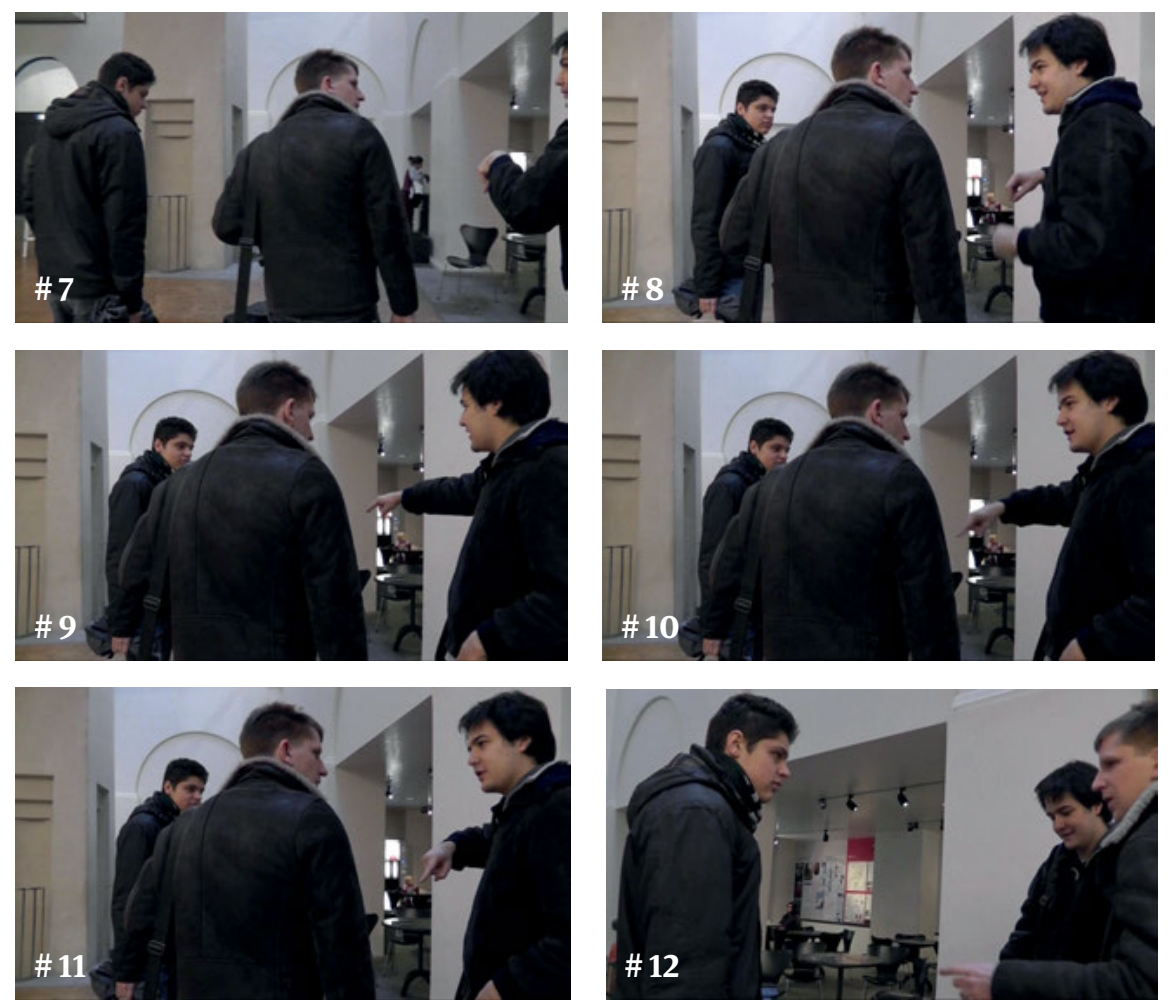

Anhand dieser Standbildfolge möchte ich zeigen, wie sich die Beteiligten signalisieren, dass sie die Hinweise im Raum, die eine Nutzung des Raums im Sinne der Ausstellungskommunikation nahelegen, nicht berücksichtigen, dass sie also für ihre Aktivität keine Rolle spielen.

- Erkennbar ist das an den Blicken der Besucher, die nicht auf die Vitrinen oder frei stehenden Exponate im Ausstellungsraum gerichtet sind und die auch nicht - wie in 5.3 als Charakteristikum des Besucherverhaltens im Ausstellungsraum beschrieben - weit in den Raum hinein gerichtet sind und jeweils der Änderung der Bewegungsrichtung im Raum vorauseilen (\#1 bis \#5). Die Blicke dieser Besuchergruppe sind vielmehr bald auf den Boden in der Nähe der Gehenden gerichtet, bald auf die anderen Mitglieder der Gruppe.

- Darüber hinaus endet die Bewegung im Ausstellungsraum hier nicht vor einem Exponat, sondern mitten auf der freien Ausstellungsfläche, also dort, wo es keine Hinweise darauf gibt, dass hier ein Gegenstand im Sinn der Ausstellungskommunikation zu nutzen wäre. Mit anderen Worten: Sie nutzen keinen der zahlreichen multimodalen Hinweise im Ausstellungsraum, die 
den Raum vor Vitrinen und Exponaten als Verweil- und Betrachtungszonen definieren.

- Stattdessen bilden die Studierenden mit ihren Körpern einen geschlossenen o-space (Kendon 1990: 212f.), der Blicke, die Gesten und die Aufmerksamkeit der Gruppenmitglieder in seinem Innern konzentriert (\#6 bis \#8). So zeigen sie sich gegenseitig an, dass ihre Körper, und nur diese, für ihre gegenwärtige Interaktionsepisode relevant sind, während die spezifischen Hinweise, die eine Nutzung des Raums für die Praxis des gemeinsamen Museumsbesuchs nahelegen, für die aktuelle Phase ihrer Interaktion keine Rolle spielen soll.

Die Behauptung, dass für die Interaktion der Studierendengruppe nur ihre Körper eine Rolle spielen sollen, geht vielleicht etwas zu weit. Denn tatsächlich nutzen sie einige basale Hinweise in ihrer räumlichen Umwelt: Sie gehen dort, wo der Raum nicht von Vitrinen oder anderen Gegenständen verstellt ist, und sie bilden dort ihren geschlossenen $o$-space, wo es zumindest keine klaren Hinweise dafür gibt, dass ein Stehenbleiben unerwünscht wäre (wie es an einer Engstelle der Fall wäre). Aber die derart für ihre Bewegung genutzten Hinweise und der durch deren Auswertung hervorgebrachte Bezug auf die räumliche Umwelt sind derart allgemein, dass hiervon das Signal ausgeht: Es ist reiner Zufall, dass dieses Gespräch gerade in diesem Raum stattfindet, in dem die Ausstellung aufgebaut ist. Es hätte beinahe überall stattfinden können: in jedem Raum nämlich, der drei Personen genügend Platz bietet, um einen geschlossenen $o$-space herzustellen.

Aus diesem Beispiel lässt sich ex negativo etwas darüber erfahren, was Raumgebundenheit als Eigenschaft von Interaktion bedeutet: Raumgebunden ist Interaktion immer dann, wenn sich die Interaktionsteilnehmer signalisieren, dass ihre Interaktion auf Hinweise Bezug nimmt, die sie aus ihrer räumlichen Umwelt gewinnen und die aus ihrer räumlichen Umwelt einen bestimmten Raum (also beispielsweise: einen Ausstellungsraum) machen. Dadurch, dass sich die Interaktionsteilnehmer anzeigen, dass ihre Interaktion auf diesen Hinweisen aufruht, wird der Raum zum spezifischen Verstehenshintergrund ihrer Handlungen (ein Blicken wird zum Betrachten eines Exponats usw.). Das Beispiel zeigt auch, dass nicht jede Interaktion im Ausstellungsraum automatisch Ausstellungskommunikation sein muss. Vielmehr kann sich die Interaktion von ihrer räumlichen Umwelt frei machen, indem sie Hinweise in der räumlichen Umwelt ignoriert oder - neutraler gesagt - nicht auswertet. 


\subsection{Fazit}

In diesem Kapitel wurden, wie schon in Kapitel5, Ausschnitte aus meinem Videokorpus untersucht, die Fälle von Kommunikation in der Ausstellung dokumentieren. Allerdings fokussierten die Analysen dieses Kapitels darauf, wie die Besucher die statischen, raum- und objektgebundenen Erscheinungsformen der Kommunikation durch die Ausstellung in ihre dynamische, körpergebundene Interaktion im Ausstellungsraum integrieren. Die leitende Frage war, wie sich die Besucher gegenseitig aufzeigen, dass sie Elemente ihrer räumlichen Umwelt für ihre Interaktion aktivieren.

Diese Frage konnte mit Hilfe des Konzepts der Lesbarkeits- und Benutzbarkeitshinweise beantwortet werden. Aus dieser Sicht aktivieren die Interaktionsbeteiligten Elemente ihrer räumlichen Umwelt, indem sie sie als Hinweise auswerten, die eine bestimmte Art der Raumnutzung oder ein bestimmtes Raumverständnis nahelegen oder erwartbar machen. Die exemplarischen Analysen dieses Kapitels haben illustriert, dass über das Hinweis-Konzept die Präzision affordance-basierter Analysen übertroffen werden kann, insbesondere dann, wenn man sich bei der Analyse der Hinweise auf die kommunikativen Teilaufgaben bezieht, die in Kapitel 3 entwickelt worden sind. Dabei wurden Strategien erprobt, um die Gefahr eines analytischen Kurzschlusses zu bannen, der jedes beobachtete Verhalten im Raum als Auswertung von Hinweisen interpretiert, die genau dieses beobachtete Verhalten nahelegen:

- die Analyse von Fällen, in denen die Interaktionsteilnehmer den Raum glatt und unauffällig nutzen, ohne dass die Raumnutzung beobachtbar die Wahrnehmungs- oder gar die Thematisierungsschwelle überschreitet; dabei ist es sinnvoll, eine Reihe ähnlich gelagerte Fälle miteinander in Beziehung zu setzen und so der Typik der Hinweis-Nutzung auf die Spur zu kommen;

- kontrastiv dazu die Analyse von Fällen, in denen der Raum problematisch oder auf unerwartete Weise genutzt wird: Fälle von body glosses, unterschiedliche Formen von Selbst- und Fremdreparaturen des Raumverhaltens, die explizite Formulierung von Regeln der Raumnutzung und der Rauminterpretation usw.; und schließlich

- der Vergleich mit den Hinweisen, die in Kapitel 3 im Ausstellungsraum rekonstruiert worden sind.

Das Hinweis-Konzept macht verständlich, warum manche Raumnutzungen häufiger zu beobachten sind als andere, unproblematischer in ihrer Durchführung sind, seltener Gegenstand von Thematisierungen und Korrekturen usw.: Es sind genau diejenigen Raumnutzungen, die an das anknüpfen, was durch Lesbarkeits- und Benutzbarkeitshinweise im Raum als präferierte Nutzung nahegelegt 
wird. Gleichzeitig bleibt das Hinweis-Konzept jedoch kompatibel zu den Grundüberzeugungen der Konversationsanalyse, insbesondere im Hinblick auf die antideterministische Vorstellung des Verhältnisses von Interaktion und Raum.

Zwar tun die Ausstellungsverantwortlichen viel dafür, dass die gewünschte Nutzung des Ausstellungsraums und seiner Objekte sichtbar wird (s.o. Kapitel 3). Und dennoch geschieht die Auswertung der Hinweise, wie wir gesehen haben, im Rahmen interaktiver Aushandlungsprozesse, in denen festgelegt wird, was als Hinweis wofür verstanden werden soll und welche Hinweise in einem Raum als dominant aufgefasst werden sollen. Besonders auffällige Aushandlungsaktivitäten konnten wir in diesem Kapitel dort beobachten, wo es für die Besucher strittig war, ob eine bestimmte Raumnutzung als transgressiv, also als Nutzung gegen die Hinweise aufgefasst werden sollte (s.o. die Ausschnitte „Labyrinth“ oder „Giraffe“). Das zeigt auch: Hinweise beruhen zwar auf etwas im Raum sinnlich Wahrnehmbaren, aber sie sind nicht ,einfach da'. Vielmehr emergieren sie in der Kommunikation, nämlich in dem Moment, in dem jemand das sinnlich wahrnehmbare Etwas als Hinweis versteht und daraus spezifische Schlüsse zieht.

Auch konnten die Analysen illustrieren, dass die Aktivierung der räumlichen Umwelt für die Interaktion auch die Auswertung von Hinweisen in der Interaktion der von der Konversationsanalyse beschriebenen grundsätzlichen Sequenzialität der Interaktion unterliegt. Bezugnahmen auf den Raum müssen initiiert werden (wie sich besonders in den Phasen zeigte, in denen sich die Besucher Hinweisen zuwenden - vergleiche den Anfang der Ausschnitte „Zaunkönig“ oder „Kibitz“), sie müssen aufrecht erhalten werden, gerade dann, wenn die Orientierung an den Hinweisen problematisch wird (vgl. den Ausschnitt „Luchs“, s.o. 5.2.5), und die Auswertung der Hinweise kann beendet werden, wie etwa im Fall der Gesprächsgruppe im Ausschnitt „Bummelstudenten“, die nach der Nutzung des Ausstellungsraums im Sinne der Ausstellungskommunikation anzeigen, dass der Raum für ihre Interaktion aktuell keine Rolle mehr spielt.

Schließlich ist die Vorstellung, dass die Aktivierung von Raumelementen für die Interaktion über die Auswertung von Hinweisen geschieht, kompatibel mit der konversationsanalytischen Denkfigur der Reflexivität von Raum und Interaktionsgeschehen. Denn insofern die Nutzung der räumlichen Umwelt für die Interaktion auf sinnlich wahrnehmbaren Erscheinungsformen beruht, die als Hinweise verstanden werden, formt der Raum die in ihm stattfindende Interaktion, er ist „action shaping“ (Mondada 2009b: 3). Hier erlaubt das Hinweiskonzept, besser zu verstehen, wie diese ,Formung‘ zustande kommt: Wenn die Besucher bei ihrem gemeinsamen Gang durch das Museum den Ausstellungsraum und seine Bestandteile für die Zwecke ihrer Interaktion aktivieren, dann machen sie die Elemente der räumlichen Umwelt, die sie als Hinweise auswerten, zum Verstehenshintergrund für ihre Aktivitäten in der Interaktion. Aus einem Stehenblei- 
ben irgendwo im Raum wird dann, wenn man es auf die im Raum unterbreiteten Hinweise bezieht, ein Stehenbleiben vor einer Vitrine oder in nützlicher Nähe zu einer Audiostation; ein Sich-Vorbeugen wird zum Studieren eines Exponats, ein Zeigen wird zu einer ,symbiotischen Geste“ im Sinne Goodwins, die leibgebundene und nicht leibgebundene semiotische Ressourcen $\mathrm{zu}$ einem ,semiotischen Feld“ verwebt (Goodwin 2003) usw. Gleichzeitig ist der Raum aber ,action shaped“ (Mondada 2009b: 3). Damit ist gemeint: Indem sich die Besucher aufzeigen, welche konkreten Hinweise sie im Raum nutzen, konstruieren sie eine ganz spezifische Sicht ihrer räumlichen Umwelt. In der Ausstellungskommunikation heißt das konkret, sie machen ihre räumliche Umwelt dadurch zum Ausstellungsraum, dass sie (neben vielem anderen, s.o. Kapitel 5) die Hinweise auf die Relevanz der Exponate, ihrer Sichtbarkeit und ihrer Verwendung zur lokalen Konstruktion von Fachwissen nutzen und sich diese Nutzung anzeigen. Das display der Hinweisnutzung in der Interaktion formt also den Raum.

Das Hinweis-Konzept erlaubt es, empirisch zu untersuchen, wie Besucher das im Ausstellungsraum vorgefundene dauerkommunikative Angebot für die Kommunikation in der Ausstellung nutzen.

Obgleich diese Analyse von der Untersuchung der Interaktion der Museumsbesucher im Ausstellungsraum ausgeht, ermöglicht es das Hinweis-Konzept, auch die Ergebnisse der Untersuchungen in Kapitel 3 in die Analyse einzubeziehen. Auf diese Weise lässt sich eine Brücke zwischen den beiden großen Analyseteilen dieser Arbeit schlagen, also der semiotisch-textlinguistischen Analyse der Bedeutungspotenziale im Ausstellungsraum (Kapitel3) und der gesprächsanalytisch inspirierten Analyse gemeinsamer Museumsbesuche (Kapitel 5). Das Hinweis-Konzept macht verständlich, wie Besucher die mit Hilfe von orts- und dingfesten, zeitbeständigen Zeichen vermittelten Bedeutungspotenziale im Ausstellungsraum nutzen können und wie sie diese in ihre dynamische Interaktion integrieren können. Sie tun das, indem sie jene Bedeutungspotenziale im Vollzug ihrer Interaktion als Hinweise auswerten, die ihnen suggerieren, wie der Raum für ihre aktuellen Interaktionszwecke zu nutzen ist, und indem sie sich diese Auswertung gegenseitig anzeigen und so interaktiv zugänglich machen.

Das Hinweiskonzept erlaubt es also, die Analyse der beiden Spielarten der Ausstellungskommunikation miteinander $\mathrm{zu}$ verzahnen und die Art und Weise, wie Besucher bei ihrem gemeinsamen Museumsbesuch das nutzen, was sie an kommunikativen Erscheinungsformen im Raum schon vorfinden, der konversationsanalytischen Untersuchung zugänglich zu machen. Durch den Einbezug der vorgängigen semiotisch-textlinguistischen Analysen des Ausstellungsraums und seiner dominanten Hinweise können die Analysen der Interaktion im Ausstellungsraum zusätzlich an Tiefe und Detail gewinnen. Denn vor der Folie der rekonstruierten Nutzungs- und Bedeutungs-Potenziale kann man die tatsächliche 
Nutzung des Raums durch Besucher, aus Fleisch und Blut' besser einschätzen. Man kann zu einer tieferen Ausdeutung des Interaktionsgeschehens gelangen, insoweit die Alternativen des Handelns und die Bedeutungsimplikationen des im Raum Vorfindlichen bereits ausgelotet sind. Auch kann die vorgängige Analyse der Hinweise im Raum für das Vorhandensein ganz unscheinbarer Hinweise im Raum sensibilisieren, oder aber das Verständnis von abweichenden Interaktionsereignissen verbessern. So konnten hier beispielsweise die Probleme, ,erlaubte، Wege durch die Ausstellung zu finden (s.o. „Labyrinth“) auf die widersprüchlichen Bewegungshinweise im Ausstellungsraum bezogen werden oder die subversive Nutzung des Giraffen-Exponats als Krabbel-Parcours mit den widerstreitenden Hinweisen, die ein Durchklettern ebenso ermöglichen und wahrscheinlich machen wie ein Betrachten.

Die in der Interaktion beobachteten Nutzungen lassen sich also in einer zukünftigen Untersuchung mit Gewinn auf die Struktur der im Raum signalisierten Nutzungspotenziale beziehen. 